Research Article

\title{
Strategic and Tactical Design of Competing Decentralized Supply Chain Networks with Risk-Averse Participants for Markets with Uncertain Demand
}

\author{
Ashkan Hafezalkotob, Ahmad Makui, and Seyed Jafar Sadjadi \\ Department of Industrial Engineering, Iran University of Science and Technology, \\ 16846113114 Tehran, Iran \\ Correspondence should be addressed to Ashkan Hafezalkotob, hafezalkotob@iust.ac.ir \\ Received 23 April 2011; Revised 18 July 2011; Accepted 11 August 2011 \\ Academic Editor: Alexander Pogromsky
}

Copyright (C) 2011 Ashkan Hafezalkotob et al. This is an open access article distributed under the Creative Commons Attribution License, which permits unrestricted use, distribution, and reproduction in any medium, provided the original work is properly cited.

\begin{abstract}
An integrated equilibrium model for tactical decisions in network design is developed. We consider a decentralized supply chain network operating in markets under uncertain demands when there is a rival decentralized chain. The primary assumption is that two chains provide partial substitutable products to the markets, and markets' demands are affected by tactical decisions such as price, service level, and advertising expenditure. Each chain consists of one riskaverse manufacturer and a set of risk-averse retailers. The strategic decisions are frequently taking precedence over tactical ones. Therefore, we first find equilibrium of tactical decisions for each possible scenario of supply chain network. Afterwards, we find optimal distribution network of the new supply chain by the scenario evaluation method. Numerical example, including sensitivity analysis will illustrate how the conservative behaviors of chains' members affect expected demand, profit, and utility of each distribution scenario.
\end{abstract}

\section{Introduction}

In an operational sense, a supply chain management (SCM) includes the management of a network of facilities, the exchange of communications, distribution channels, and the firms that procure materials, transform these materials to intermediate and finished products, and distribute the finished products to customer. However, in an organizational sense, a supply chain (SC) consists of a broad variety of collaborative agreements and contracts among independent enterprises, which integrates them as collaborative networks. These enterprises normally pursue conflicting goals extended across production, purchasing, inventory, transportation, and marketing $[1,2]$.

There are many studies, which indicate that the competition is evolving from companies to their SCs [3-7]. For example, rival SCs of Toyota and Honda open manufacturing 
facilities in every major market where they enter to be more responsive to the customers [8], and Microsoft (software supplier) and HTC (device manufacturer) constitute an SC to compete with other SCs such as Symbian (software supplier) and Nokia (device manufacturer) [3]. There are two important factors affecting the efficiency of a company's supply chain. The first is associated with the competitors, and the second one is due to conflicting goals among SC participants, which reduce the efficiency of a decentralized chain.

From the system management prospective, decisions of participants in an SC may be categorized as three levels or phases including strategic (design phase), tactical (planning phase), and operational levels, depending on the frequency of decisions and the time frame during which these decisions are made [8,9]. Long-range SC management issues such as supply chain network design (SCND), capacities of facilities, logistic network, and longterm contract need to be planned at the strategic level [9]. For the fixed SC's configuration determined in strategic level, mid-range activities such as transportation, procurement, and inventory polices are planned and synchronized through tactical level [8]. At the operational level, daily or weekly tasks in the SC must be managed to handle incoming customer orders. At this level, SC configuration is considered stabilized, and planning policies are already defined. Therefore, SCs strategies in competitive market should be considered based on this hierarchical decision making structure. In the competitive models based on game theory, these sequential and noncooperative strategies conform to Stackelberg strategies rather than Nash strategies $[1,10]$. There are several concerns in a supply chain decision making such as how independent participants of an SC manage coordination to confront their rival SCs and how strategic, tactical, and operational decisions of participants in one chain affect such decisions of participants in the rival chain.

In many industries, decision makers of SCs encounter high uncertainty regarding customers' behavior and their demand [11]. For example, many automotive corporations may find it difficult to handle the changes in customer preferences and demand fluctuations [2]. Although all three levels of decisions are affected from demand uncertainty, incorporating this uncertainty in SC configuration design is extremely important because these decisions are hard and costly to change in short time. For example, in late 1990s, Toyota made its global assembly plants more flexible so that each plant could supply multiple market demands to cope with demand and price uncertainties [8]. High level of flexibility along with competitive pricing derived from efficient SC allows Toyota to overcome fluctuation in demand, exchange rate, and local prices and maximize and stabilize profit in highly competitive automotive industry.

Uncertainty in demand brings about uncertainty in profits of all firms through a chain. The risk attitude of a firm determines sensitivity towards profit or demand uncertainty [3]. Risk-neutral firms are completely indifferent to risk involved profit uncertainty, and they only concern about expected profit. However, risk-averse firms avoid risk by minimizing profit fluctuation as well as maximizing expected profit. Since participants of an SC may have different attitudes towards risk of demand uncertainty, various risk structures can be considered for two competitive supply chain networks.

SCND concerns structuring physical network or distribution channels to minimize (maximize) cost (profit). Although SCND is significantly affected from rival chain decisions, except Rezapour and Farahani [4], all previous researchers neglected the competitive environment and its effects on the design. We generalize competitive SCND introduced in [4] for decentralized supply chains under demand uncertainty. Furthermore, we incorporate various risk attitudes of SC participants into SCND and tactical strategies such as pricing, service level, and advertisement expenditure. For instance, Mercedes Benz, a leading edge 
car manufacturer, should respond to the structural changes in its industry and the challenges it faces from distribution channels [12]. The company uses distribution channels, which include national sale organizations (NSOs). NSOs offer country-specific features and services to markets which they cover (supply). Moreover, NSOs together with Mercedes Benz decide pricing strategy in those particular markets. Due to social status of Mercedes Benz, the markets structures, and the company's competitive position in different markets, Mercedes Benz and NSOs pursue different service level and prices for the markets (which is referred to as price discrimination). For example, Mercedes Benz prices for an exactly same model tremendously vary from the USA to some Asian countries.

The paper is organized as follows. In Section 2, the related literature is reviewed. Section 3 includes a discussion of the problem and related notations. The basic model of the competition between SCs with risk-averse participants is formulated in Section 4. This section also provides a scenario evaluation method for the model. Section 5 presents some computation results including a numerical example and its sensitivity analysis. Finally, the paper concludes in Section 6 with some directions for future research in this area.

\section{Literature Review}

For any manufacturer with a product to sell, how to make that product available to the intended markets can be as essential a strategic issue as developing the product itself. The manufacturers commonly confront several choices of distribution channels which can be classified based on channel control of the manufacturer over intermediaries and single or hybrid type of channels (we refer the reader to [13] for further discussion on classification of multichannel distribution). Our paper is related to the class of single manufacturer with multiple independent retailers.

A stream of multichannel distribution literature exists that deals with multiple retailers, where retailers do not interact with each other. Each retailer covers (supplies) specific markets, and the manufacturer sufficiently produces to satisfy all retailer demands [13]. Ingene and Parry [14] investigated two part tariff wholesale pricing policy, common to all retailers. Netessine and Rudi [15], Fransoo et al. [16], and Chen et al. [17] also took multiple independent retailers into account which sell products of a single manufacturer. They analyzed how decentralized decisions of inventory control affect the cost of SC's members. Our major contributions in multichannel distribution may be summarized as follows: (i) while in multichannel distribution literature, the structure of channels is commonly assumed fixed, we consider that the manufacturer has the initiative to select distribution network from a set of possible scenarios. The scenarios are evaluated for their expected profit and risk entailed for the manufacturer. (ii) There is a rival SC offering substitutable products to all markets, thus all tactical decisions in the markets should be taken in response to the rival SC. (iii) We also involve global advertising expenditure of the manufacturer along with traditional tactical decisions price and service level.

Pricing is a significant decision, and competing companies regularly play a price war to attract customers. Several researchers considered that market's demand depends on price of products over planning horizon [4, 18-24]. Similar approaches have also been used in the cases where both marketing and pricing influence demand [25-28]. On the other hand, leader producers pay considerable advertising expenditure to build strong brand and develop markets [29]. Gasmi et al. [30] showed that demand is affected by price of substitutable products and advertisement expenditures of rivals in a competitive market environment, and their demand structure is followed by other researchers in various industries [31-33]. 
Service level is another important factor affecting the buying decisions of customers in many industries [3], and some researchers consider combinatory impact of price and service level on demand under uncertainty [3,34-38]. To the best of our knowledge, it is the first paper which generalizes previous demand functions by considering demand of markets depending on products price, service levels, and advertising expenditures of competitive firms (or SCs).

Strategic decisions such as SCNDs have long-term impact on SC's performance, and managers must account for demand, macroeconomic, and financial uncertainties when they are designing an SCN. Therefore, several researchers such as Mirhassani et al. [39] and Tsiakis et al. [40] considered demand uncertainty represented by multiple demand scenarios in SCND. Santoso et al. [41] developed a stochastic model for SCND, which allows for uncertainty in processing/transportation costs, demand, supplies, and capacities and for limited, but a very large number of scenarios representing uncertainty in demand, as well as in other parameters. Nevertheless, from interesting viewpoint of decentralized SC, independent decision makers of an SC involve in competitive facility location. Nagurney et al. [42] remarkably suggested a supply chain network equilibrium (SCNE) model for studying the economic behavior of the decentralized SC with market competition which was formulated by variational equalities. Subsequently, SCNE model has been developed for markets with random demands [43]. SCNE has attracted more attention recently [18, 4448]. We account for designing an SC with regard to the existing rival chain under demand uncertainty, and we assume that tactical decisions are taken in the decentralized manner; however, the leader of supply chain determines strategic decisions of SCND.

Location and allocation problem in the real world applications involves optimization over a large number of discrete variables. Consequently, such strategic decisions that configure supply network are complex, and realistically sized problems can only be solved with heuristic technique. We refer the reader to [49] for review application of heuristic and metaheuristic optimization techniques to SCND. In spite of considerable advances in optimization algorithms for solving distribution system design problems, scenario evaluation method is also a reasonable method for investigating distribution network designs, which is frequently used in the real problem facing managers [50]. Scenario evaluation belongs to the nonoptimizing class of design methodology, which chooses favorable distribution scenario by employing techniques of multicriteria decision making (MCDM), or other interactive methods with decision maker. Robinson and Swink [51] discussed possible methodologies for network design problem and used a scenario evaluation for a realistically sized problem. Moreover, Robinson and Swink [50] experimentally examined human abilities to evaluate the distribution scenarios in distribution system design problems.

Uncertainty over customer behaviors brings about risk for partners in SCs. Different attitudes of the partners towards risk profoundly influence supply chain interactions and members' decisions [3, 11]. Tsay [11] discussed the effect of different return policies on manufacturer-retailer relationship under various scenarios of relative strategic power. He discussed that in such a relationship, manufacturer and retailer should consider which of them can absorb risk better. Xiao and Yang [34] developed an information revelation mechanism model of a two-echelon supply chain facing an outside competitor. Yang et al. [38] developed a competition model based on price, service level, and lot size for a supply chain with one supplier and two risk-averse retailers. They investigated the effect of risk attitude of a retailer on his decisions as well as his rival retailer's decisions. We focus on two competitive SCs which each participant of them has independent sensitivity towards risk derived from uncertain demand. 


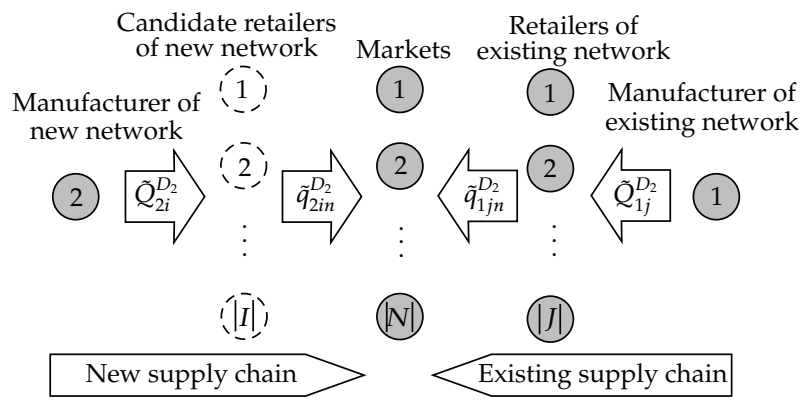

Figure 1: Structure of the competitive supply chains.

Our paper is closely related to $[3,4]$; however it is different and more comprehensive according to the following aspects. Xiao and Yang [3] developed a price and service competition model of one-manufacturer and one-retailer supply chains to study the optimal decisions of the players under demand uncertainty. They analyzed the effects of the retailer risk sensitivity on the optimal strategies of players and the optimal price-service decisions of the rival. Unlike Xiao and Yang, we consider an SCND problem for two competitive chains with various risk attitudes for both manufacturer and retailer. Rezapour and Farahani [4] developed an equilibrium model for strategic design of a centralized SCN in markets with deterministic demand encountering a competitive chain. However, the decision structure is different because we consider decentralized SCs under demand uncertainty. Our paper is also closely related to what was developed in [12], which investigates competitive facility location problem in a three-tier decentralized SC when an external firm intends to enter the SC. They did not consider SCs competition in SCND as well as demand uncertainty, which are mainly studied in our model. Combination of SCND with tactical decisions accompanied by considering risk attitude for all participants gives the research an original contribution to define supply chains competition model in an uncertain environment based on mathematical elements of game theory.

\section{Problem Statement}

We account for a decentralized SCN embracing one manufacturer and a set of retailers in markets with stochastic demands in presence of a rival decentralized SC. Manufacturers and retailers in both SCs are risk averse. Products of two chains (the existing and new chains) are partially differentiated, and the manufacturer in each chain sells products in each market through the retailer determined for that market as illustrated in Figure 1.

The problem structure and related assumptions of the research are as follows.

\subsection{Specifications of Facilities in SCNs}

(i) Except demand of markets, all parameters are deterministic and known in advance.

(ii) In the new SC, the manufacturer faces several possible scenarios of distribution design to distribute his products in the markets. In each scenario, the location of candidate retailers and the markets that each retailer can supply are known.

(iii) The existing SC provides markets with substitutable products. The distribution network structure of the existing SC is fixed and known in advance. 
(iv) The markets are geographically dispersed, and they are independent of each other (see [52]).

(v) Retailers of networks combine the demands from corresponding markets and order from the manufacturer.

(vi) Retailers for corresponding markets offer service levels; however, manufacturers invest in advertisement to increase the demand of all markets and promote brand positioning. The manufacturer sets the wholesale price, and the retailers set the retail price considering transportation costs.

(vii) Manufacturers and retailers in both SCs have infinitive capacities (their capacities are large enough).

\subsection{Demand of Markets}

(i) Demand of markets is composed of deterministic and stochastic parts. Parameters of stochastic part are known for decision makers of SCs.

(ii) Deterministic part of the markets' demands depends on product price, service levels, and market expenditures of two competitive SCs.

\subsection{Cost Parameters in SCNs}

(i) Purchasing price of products in a market includes wholesale price of manufacturer, profit margin of retailers, transportation cost between manufacturer and retailer, and transportation cost between retailer and market.

(ii) Each manufacturer has a specific production cost.

(iii) Retailers incur different cost for providing service level because their service level efficiencies vary.

\subsection{Sequence of Decision Making in SCs}

With regard to time sequence of strategic and tactical decisions of an SC, we consider the two following stages in competitive game structure.

Stage 1. The manufacture in new supply chain evaluates each possible scenario of distribution design (a set of distribution channels) and selects the scenario with the highest utility. In each scenario, the active retailers and the set of markets which are covered by each retailer are specified.

Stage 2. Participants in both competitive chains take tactical decisions in decentralized manner. That is to say, manufacturers and retailers jointly determine product price, service levels, and advertising expenditures in a noncooperative fashion.

The distribution network scenarios are defined based on a possible network of a single manufacturer and multiple retailers where retailers do not interact with each other. This generalization allows products to flow through multiple independent retailers while each retailer has specific and predetermined territories. Objectives of each participant in SC are to maximize profit and minimize risk of profit fluctuation. The relative importance of these objectives is determined by risk sensitivity parameter. 
Parameters of our model are as follows:

(i) candidate retailers and their locations in new SC;

(ii) cost elements of both chains;

(iii) deterministic part and parameters of stochastic part of the markets demand for both SCs;

(iv) risk sensitivity of participants in both SCs.

\section{Model}

Existing and new SCs are denoted by indices one and two, respectively. We have the following notations, indices, parameters, and decision variables.

\subsection{Sets and Indices}

$N$ : The set of demand markets; $N=\{1,2, \ldots,|N|\}, n \in N$.

$I$ : The set of candidate retailers in new SC; $I=\{1,2, \ldots,|I|\}, i \in I$.

$J$ : The set of retailers in existing SC; $J=\{1,2, \ldots,|J|\}, j \in J$.

$N_{1}$ : The partition of set $N$, which indicates how markets are supplied by retailers of the existing SC; $N_{1}=\left\{N_{11}, N_{12}, \ldots, N_{1|J|}\right\}$.

$N_{2}^{D_{2}}$ : The partition of set $N$, which indicates how markets are supplied by retailers of the new SC under condition of scenario $D_{2}$ of SC design; $N_{2}^{D_{2}}=\left\{N_{21}^{D_{2}}, N_{22}^{D_{2}}, \ldots, N_{2|I|}^{D_{2}}\right\}$.

$N_{1 j}, N_{2 i}^{D_{2}}$ : The subset of demands market set $N$ supplied by the retailer $j$ in the existing SC, and subset of demands market set $N$ supplied by the retailer $i$ in the new SC under conditions of scenario $D_{2}$, respectively.

$D_{1}$ : The design of the existing SC, which is fixed and determined by partition $N_{1}$.

\subsection{Parameters}

$\tilde{\alpha}_{1 n}$ : The stochastic part of $n$th market's demand for product type 1 of the existing SC with mean $\bar{\alpha}_{1 n}>0$, variance $\sigma_{1 n}^{2}$.

$\tilde{\alpha}_{2 n}$ : The stochastic part of $n$th market's demand for product type 2 of the new SC with mean $\bar{\alpha}_{2 n}>0$, variance $\sigma_{2 n}^{2}$.

$c_{1}, c_{2}$ : The unit production costs of the manufacturer in the existing and new SCs, respectively.

$d$ : The substitutability coefficient for the two products; $0<d<1$,

$\beta_{n}$ : The demand sensitivity of one retailer to his own service level in $n$th market; $\beta_{n}>0$,

$\gamma_{n}$ : The demand sensitivity of one retailer to the rival's service level in $n$th market, namely, cross-service level coefficient; $\beta_{n}>\gamma_{n}>0$.

$\rho_{n}$ : The demand sensitivity of one retailer to his manufacturer's advertising expenditure in $n$th market; $\rho_{n}>0$.

$v_{n}$ : The demand sensitivity of one retailer to the advertising expenditure of the rival manufacturer in the $n$th market, namely, cross-advertising coefficient, 
$\eta_{1 j}, \eta_{2 i}$ : The service investment efficiency coefficient of retailer $j$ in the existing SC and retailer $i$ in the new SC, $\eta_{1 j}, \eta_{2 i}>0$. The larger the coefficient $\eta_{1 j}\left(\eta_{2 i}\right)$, the lower the service investment efficiency of retailer $j(i)$ will be.

$T C_{1 j}, T C_{2 i}$ : The cost of transportation of a unit of product between manufacturer and $j$ th retailer in the existing SC and between manufacturer and ith retailer in the new $\mathrm{SC}$, respectively; $T C_{1 j}, T C_{2 i}>0$.

$T C_{1 j n}, T C_{2 i n}$ : The cost of transportation of a unit of product between $j$ th retailer and demand market $n$ in the existing SC and between $i$ th retailer and demand market $n$ in the new SC, respectively; $T C_{1 j n}, T C_{2 i n}>0$.

$\lambda_{R_{1 j}}, \lambda_{R_{2 i}}$ : The sensitivity to risk or the constant absolute risk aversion (CARA) of retailers $j$ and $i$, respectively, which is defined in Arrow-Pratt sense; $\lambda_{R_{1 j}}, \lambda_{R_{2 i}} \geq 0$.

$\lambda_{M_{1}}, \lambda_{\mathrm{M}_{2}}$ : The sensitivity to risk or the constant absolute risk aversion (CARA) of manufacturers in the existing and new SCs, respectively; $\lambda_{M_{1}}, \lambda_{M_{2}} \geq 0$.

\subsection{Decision Variables}

$D_{2}$ : The possible distribution design scenario of the new SC comprising a set of candidate retailers and a set of markets which each candidate retailer is able to cover and supply.

$w_{1}, w_{2}$ : The unit wholesale prices of the manufacturer in the existing and new SCs, respectively.

$m_{1 j}, m_{2 i}$ : The profit margin of retailer $j$ in the existing SC and the profit margin of retailer $i$ in the new SC, respectively.

$p_{1 j n}$ : The price of existing SC's product offered by retailer $j$ in $n$th market; $p_{1 j n}=w_{1}+$ $T C_{1 j}+m_{1 j}+T C_{1 j n}$.

$p_{2 i n}$ : The price of new SC's product offered by retailer $i$ in $n$th market; $p_{2 i n}=w_{2}+T C_{2 i}+$ $m_{2 i}+T C_{2 i n}$.

$s_{1 j}, s_{2 i}$ : The service level of retailer $j$ in the existing SC and the service level of retailer $i$ in the new SC, respectively.

$a_{1}, a_{2}$ : The advertising expenditures of manufacturers in the existing and new SCs, respectively.

In both SCs, manufacturer sets a wholesale price for all his retailers, and each retailer determines a profit margin for all assigned markets. Consequently, retail price of SC's product at each market is the sum of wholesale price, corresponding retailer's profit margin, and transportation costs between manufacturer and retailer and between retailer and the market. Transportation costs are affected by geographical location of facilities, transportation modes, available vehicles, and route and distances among facilities. In our paper, products of the new SC get considerable competitive advantages if the configuration of the chain helps the participants offer products to the markets with the lowest possible retail price.

\subsection{Demand Function in the Markets}

In Section 2, we mentioned that price, service level, and advertising expenditure are important factors influencing markets demand, which are separately or geminately investigated by 
several researchers. By considering demand function sensitive to price and service level [3, $34,35,38]$ and well-known demand function sensitive to price and advertising expenditure [30-33], we assume that under the condition of the distribution deign scenario $D_{2}$ for the new $\mathrm{SC}$, the demand at $n$th market for products offered by retailer $j$ is

$$
\tilde{q}_{1 j n}^{D_{2}}=\tilde{\alpha}_{1 n}-p_{1 j n}+d p_{2 i n}+\beta_{n} s_{1 j}-\gamma_{n} s_{2 i}+\rho_{n}\left(a_{1}\right)^{1 / 2}+v_{n}\left(a_{2}\right)^{1 / 2} .
$$

Index $i$ refers to the rival retailer who covers $n$th market, that is determined by distribution design scenario $D_{2}$ (we show this as for all $n, i \rightarrow D_{2}$ ). Moreover, under the condition of $D_{2}$, the demand at $n$th market for products offered by retailer $i$ is

$$
\tilde{q}_{2 i n}^{D_{2}}=\tilde{\alpha}_{2 n}-p_{2 i n}+d p_{1 j n}+\beta_{n} s_{2 i}-\gamma_{n} s_{1 j}+\rho_{n}\left(a_{2}\right)^{1 / 2}+v_{n}\left(a_{1}\right)^{1 / 2}
$$

where retailer $j$ which covers $n$th market is determined and fixed by design $D_{1}$ of the existing SC (i.e., for all $n, j \rightarrow D_{1}$ ). Although both SCs designs affect demand of markets and since the configuration of the existing SC $\left(D_{1}\right)$ is assumed fixed in the competition, we only involve the impact of distribution design scenario $D_{2}$ upon market demands (4.1) and (4.2). Mean and variance of market vary from market to market depending on customers' behavior and their perception of quality, brand, reputation, position, and so on. Each market demand of each retailer is an increasing function of his rival's retail price, his own service level, and his manufacturer's advertising expenditure, however, a decreasing function of his own retail price and his rival's service level. Note that similar to [30,53], we do not compel a limitation regarding the sign of cross-advertising coefficient $v_{n}$. The essence of advertising in $n$th market is called predatory if $v_{n}<0$ and cooperative if $v_{n}>0$. In general, a manufacturer might be capable of selecting the essence of his advertising; however, that possibility is ignored here.

\subsection{Profit and Utility Functions of Participants in SCs}

The quantity ordered by retailer $j$ to his manufacturer is equal to the sum of markets' demands which the retailer covers (supplies) under the condition of design $D_{1}$; therefore, we may write

$$
\widetilde{Q}_{1 j}^{D_{2}}=\sum_{\substack{n \in N_{1 j} \\ \forall n, i \rightarrow D_{2}}} \tilde{q}_{1 j n}^{D_{2}}=\sum_{\substack{n \in N_{1 j} \\ \forall n, i \rightarrow D_{2}}}\left(\tilde{\alpha}_{1 n}-p_{1 j n}+d p_{2 i n}+\beta_{n} s_{1 j}-\gamma_{n} s_{2 i}+\rho_{n}\left(a_{1}\right)^{1 / 2}+v_{n}\left(a_{2}\right)^{1 / 2}\right) .
$$

Similarly, the quantity ordered by retailer $i$ to his manufacturer is equal to

$$
\widetilde{Q}_{2 i}^{D_{2}}=\sum_{\substack{n \in N_{2 i}^{D_{2}} \\ \forall n, j \rightarrow D_{1}}} \tilde{q}_{2 i n}^{D_{2}}=\sum_{\substack{n \in N_{2 i}^{D_{2}} \\ \forall n, j \rightarrow D_{1}}}\left(\tilde{\alpha}_{2 n}-p_{2 i n}+d p_{1 j n}+\beta_{n} s_{2 i}-\gamma_{n} s_{1 j}+\rho_{n}\left(a_{2}\right)^{1 / 2}+v_{n}\left(a_{1}\right)^{1 / 2}\right) .
$$

In (4.3) and (4.4), pairs of retailers $j$ and $i$ regarding each market are determined by fixed design $D_{1}$ and distribution design scenario $D_{2}$, respectively. Index $D_{2}$ in $Q_{1 j}^{D_{2}}$ and $Q_{2 i}^{D_{2}}$ indicates that the total quantities ordered by retailers only depend on the new SC configuration (the configuration of the existing SC is fixed). 
Similar to $[3,34,35,38,54]$, we assume that service level cost functions of retailers $j$ and $i$ are $(1 / 2) \eta_{1 j} s_{1 j}{ }^{2}$ and $(1 / 2) \eta_{2 i} s_{2 i}{ }^{2}$, respectively; that is, enhancing service level has a diminishing influence on service level expenditure. Taking ordered quantities (4.3) and (4.4) into account, the random profits of retailer $j$ and $i$, in turn, are as follows:

$$
\begin{aligned}
\tilde{\pi}_{R_{1 j}}^{D_{2}}= & m_{1 j} \sum_{\substack{n \in N_{1 j} \\
\forall n, i \rightarrow D_{2}}}\left(\tilde{\alpha}_{1 n}-p_{1 j n}+d p_{2 i n}+\beta_{n} s_{1 j}-\gamma_{n} s_{2 i}+\rho_{n}\left(a_{1}\right)^{1 / 2}+v_{n}\left(a_{2}\right)^{1 / 2}\right) \\
& -\frac{1}{2} \eta_{1 j} s_{1 j}{ }^{2}, \quad \forall j \in J, \\
\tilde{\pi}_{R_{2 i}}^{D_{2}}= & m_{2 i} \sum_{\substack{n \in N_{2 i}^{D_{2}} \\
\forall n, j \rightarrow D_{1}}}\left(\tilde{\alpha}_{2 n}-p_{2 i n}+d p_{1 j n}+\beta_{n} s_{2 i}-\gamma_{n} s_{1 j}+\rho_{n}\left(a_{2}\right)^{1 / 2}+v_{n}\left(a_{1}\right)^{1 / 2}\right) \\
& -\frac{1}{2} \eta_{2 i} s_{2 i}{ }^{2}, \quad \forall i \in I,
\end{aligned}
$$

where $p_{1 j n}=w_{1}+T C_{1 j}+m_{1 j}+T C_{1 j n}$ and $p_{2 i n}=w_{2}+T C_{2 i}+m_{2 i}+T C_{2 i n}$.

The quantity produced by manufacturer in each SC is equal to the sum of quantities ordered by all retail outlets. The total profit of each manufacturer is equal to the profit margin of the manufacturer times the total quantity of the product purchased by all retailers minus the advertising expenditure. Therefore, the random profits of manufacturers in the new and existing SCs, in turn, are as follows:

$$
\begin{aligned}
& \tilde{\pi}_{M_{1}}^{D_{2}}=\left(w_{1}-c_{1}\right) \sum_{j \in J} \sum_{\substack{n \in N_{1 j} \\
\forall n, i \rightarrow D_{2}}}\left(\tilde{\alpha}_{1 n}-p_{1 j n}+d p_{2 i n}+\beta_{n} s_{1 j}-\gamma_{n} s_{2 i}+\rho_{n}\left(a_{1}\right)^{1 / 2}+v_{n}\left(a_{2}\right)^{1 / 2}\right)-a_{1}, \\
& \tilde{\pi}_{M_{2}}^{D_{2}}=\left(w_{2}-c_{2}\right) \sum_{i \in I} \sum_{\substack{n \in N_{2 i}^{D_{2}} \\
\forall n, j \rightarrow D_{1}}}\left(\tilde{\alpha}_{2 n}-p_{2 i n}+d p_{1 j n}+\beta_{n} s_{2 i}-\gamma_{n} s_{1 j}+\rho_{n}\left(a_{2}\right)^{1 / 2}+v_{n}\left(a_{1}\right)^{1 / 2}\right)-a_{2}
\end{aligned}
$$

where $p_{1 j n}=w_{1}+T C_{1 j}+m_{1 j}+T C_{1 j n}$ and $p_{2 i n}=w_{2}+T C_{2 i}+m_{2 i}+T C_{2 i n}$.

Randomness of market demand involves uncertainty in the above profit functions. Manufacturers and retailers may have different risk attitudes towards this uncertainty. That is to say, risk-neutral retailers (manufacturers) are completely insensitive to profit fluctuations; however, risk averse retailers (manufacturers) determine their strategies to reduce profit uncertainty. It is an undeniable fact that firms do care about risk, and different firms may care to different extents [11]. Unlike Xiao and Yang [3, 34], we assume that manufacturer as well as his retailers can be risk-averse based on their individual preferences. Bar-Shira and Finkelshtain [55] stated that using the utility function, which raises the mean and reduces variance, is more robust than approaches based on expected utility. Consequently, it is assumed that each player assesses random profit function via a utility function $\{E(\tilde{\pi})-$ $\lambda \operatorname{Var}(\tilde{\pi})\}$; that is, utility function of each player is an increasing function of his expected profit, however, a decreasing function of profit uncertainty and his sensitivity to risk. By using mean-variance concept for random profits (4.5)-(4.6), retailers and manufacturers in the existing and new SCs, in turn, assess the following utilities for the random profit 
(we refer the reader to $[3,11,34,35,56,57]$ ):

$$
\begin{aligned}
u_{R_{1 j}}\left(\tilde{\pi}_{R_{1 j}}^{D_{2}}\right)= & m_{1 j} \sum_{\substack{n \in N_{1 j} \\
\forall n, i \rightarrow D_{2}}}\left(\bar{\alpha}_{1 n}-p_{1 j n}+d p_{2 i n}+\beta_{n} s_{1 j}-\gamma_{n} s_{2 i}+\rho_{n}\left(a_{1}\right)^{1 / 2}+v_{n}\left(a_{2}\right)^{1 / 2}\right) \\
& -\frac{1}{2} \eta_{1 j} s_{1 j}{ }^{2}-\lambda_{R_{1 j}} m_{1 j}^{2} \sum_{n \in N_{1 j}} \sigma_{1 n}^{2}, \quad \forall j \in J, \\
u_{R_{2 i}}\left(\tilde{\pi}_{R_{2 i}}^{D_{2}}\right)= & m_{2 i} \sum_{\substack{n \in N_{2 i}^{D_{2}} \\
\forall n, j \rightarrow D_{1}}}\left(\bar{\alpha}_{2 n}-p_{2 i n}+d p_{1 j n}+\beta_{n} s_{2 i}-\gamma_{n} s_{1 j}+\rho_{n}\left(a_{2}\right)^{1 / 2}+v_{n}\left(a_{1}\right)^{1 / 2}\right) \\
& -\frac{1}{2} \eta_{2 i} s_{2 i}{ }^{2}-\lambda_{R_{2 i}} m_{2 i}^{2} \sum_{n \in N_{2 i}^{D_{2}}} \sigma_{2 n}^{2}, \quad \forall i \in I, \\
u_{M_{1}}\left(\tilde{\pi}_{M_{1}}^{D_{2}}\right)= & \left(w_{1}-c_{1}\right) \sum_{j \in J} \sum_{\substack{n \in N_{1 j} \\
\forall n, i \rightarrow D_{2}}}\left(\bar{\alpha}_{1 n}-p_{1 j n}+d p_{2 i n}+\beta_{n} s_{1 j}-\gamma_{n} s_{2 i}+\rho_{n}\left(a_{1}\right)^{1 / 2}+v_{n}\left(a_{2}\right)^{1 / 2}\right) \\
& -a_{1}-\lambda_{M_{1}}\left(w_{1}-c_{1}\right)^{2} \sum_{n \in N} \sigma_{1 n}^{2}, \\
& -a_{2}-\lambda_{M_{2}}\left(w_{2}-c_{2}\right)^{2} \sum_{n \in N} \sigma_{2 n}^{2}, \\
u_{M_{2}}\left(\tilde{\pi}_{M_{2}}^{D_{2}}\right)= & \left(w_{2}-c_{2}\right) \sum_{i \in I} \sum_{\substack{n \in N_{2 i}^{D_{2}} \\
\forall n \rightarrow D_{1}}}\left(\tilde{\alpha}_{2 n}-p_{2 i n}+d p_{1 j n}+\beta_{n} s_{2 i}-\gamma_{n} s_{1 j}+\rho_{n}\left(a_{2}\right)^{1 / 2}+v_{n}\left(a_{1}\right)^{1 / 2}\right)
\end{aligned}
$$

where $p_{1 j n}=w_{1}+T C_{1 j}+m_{1 j}+T C_{1 j n}$ and $p_{2 i n}=w_{2}+T C_{2 i}+m_{2 i}+T C_{2 i n}$.

In utility functions (4.7)-(4.10), $\lambda_{R_{1 j}}, \lambda_{R_{2 i}}, \lambda_{\mathrm{M}_{1}}$, and $\lambda_{M_{2}}$ are constant relative risk aversions (CARAs) which specify risk attitude of retailers and manufacturers towards uncertainty. Zero value for CARA means that participant is risk neutral; conversely, $\lambda_{R_{1}}, \lambda_{R_{2 i}}, \lambda_{M_{1}}, \lambda_{M_{2}}>0$ indicates risk-averse behavior of participants, and the higher the CARA, the more conservative their behavior will be.

With regard to sequence of decision making in SCs (in Section 3.4), in the first place, the tactical designs for a given distribution design scenario will be analyzed; afterwards, the optimal scenario for distribution network (SC configuration) is investigated in Section 4.7.

\subsection{The Equilibrium Condition for Tactical Decisions}

The goal of tactical decisions is to maximize SC surplus that can be generated over planning horizon given the constraint established through design phase (strategic decisions) [8]. In the planning phase of our decentralized SCs, given SCs designs $N_{1}$ and $N_{2}^{D_{2}}$, retailers determine profit margin and service level, and manufacturers specify wholesale price as well as marketing expenditure to maximize their own utility. 
Hessian matrices of $u_{R_{1 j}}\left(\tilde{\pi}_{R_{1 j}}^{D_{2}}\right)$ and $u_{R_{2 i}}\left(\tilde{\pi}_{R_{2 i}}^{D_{2}}\right)$ with respect to profit margin and service level decisions, in turn, are

$$
\begin{gathered}
H_{R_{1 j}}=\left[\begin{array}{cc}
-2\left(\left|N_{1 j}\right|+\lambda_{R_{1 j}} \sum_{n \in N_{1 j}} \sigma_{1 n}^{2}\right) & \beta_{n}\left|N_{1 j}\right| \\
\beta_{n}\left|N_{1 j}\right| & -\eta_{1 j}
\end{array}\right], \\
H_{R_{2 i}}^{D_{2}}=\left[\begin{array}{cc}
-2\left(\left|N_{2 i}^{D_{2}}\right|+\lambda_{R_{2 i}} \sum_{n \in N_{2 i}^{D_{2}}} \sigma_{2 n}^{2}\right. & \left.\beta_{n}\left|N_{2 i}^{D_{2}}\right|\right] \\
\beta_{n}\left|N_{2 i}^{D_{2}}\right| & -\eta_{2 i}
\end{array}\right] .
\end{gathered}
$$

Furthermore, Hessian matrices of $u_{M_{1}}\left(\tilde{\pi}_{M_{1}}^{D_{2}}\right)$ and $u_{M_{2}}\left(\tilde{\pi}_{M_{2}}^{D_{2}}\right)$ with regard to wholesale price and advertising expenditure decisions are as follows

$$
H_{M_{k}}=\left[\begin{array}{cc}
-2\left(|N|+\lambda_{M_{k}} \sum_{n \in N} \sigma_{1 n}^{2}\right) & \frac{a_{k}^{-1 / 2}}{2} \sum_{n \in N} \rho_{n} \\
\frac{a_{k}^{-1 / 2}}{2} \sum_{n \in N} \rho_{n} & -\frac{\left(w_{k}-c_{k}\right) a_{k}^{-3 / 2}}{4} \sum_{n \in N} \rho_{n}
\end{array}\right], \quad k=1,2
$$

$|N|,\left|N_{1 j}\right|$, and $\left|N_{2 i}^{D_{2}}\right|$ represent cardinality of $N, N_{1 j}$, and $N_{2 i}^{D_{2}}$, respectively. The utility functions of retailers and manufacturers in the existing and new $\mathrm{SC}$ s are concave functions on corresponding tactical decisions if and only if Hessian matrices $H_{R_{1 j}}, H_{R_{2 i}}, H_{M_{1}}$, and $H_{M_{2}}$ are negative definite, respectively. Let us now define

$$
\begin{gathered}
B_{1 j}=\left|N_{1 j}\right|+\lambda_{R_{1 j}} \sum_{n \in N_{1 j}^{D_{1}}} \sigma_{1 n}^{2}-\frac{\left(\beta_{n}\left|N_{1 j}\right|\right)^{2}}{2 \eta_{1 j}}, \\
B_{2 i}^{D_{2}}=\left|N_{2 i}^{D_{2}}\right|+\lambda_{R_{2 i}} \sum_{n \in N_{2 i}^{D_{2}}} \sigma_{2 n}^{2}-\frac{\left(\beta_{n}\left|N_{2 i}^{D_{2}}\right|\right)^{2}}{2 \eta_{2 i}}, \\
A_{M_{k}}=|N|+\lambda_{M_{k}} \sum_{n \in N} \sigma_{k n}^{2}-\frac{\left(\sum_{n \in N} \rho_{n}\right)^{2}}{4}, \quad k=1,2 .
\end{gathered}
$$

Given SCs' designs, the optimal tactical decisions in the equilibrium state are obtained from the following proposition. 
Proposition 4.1. If $B_{1 j}>0$, for all $j \in J, B_{2 i}^{D_{2}}>0$, for all $i \in I$, and $A_{M_{1}}, A_{M_{2}}>0$, then the optimal profits margins of all retailers $j \in J$ and $i \in I$ satisfy the following linear system of equations:

$$
\begin{aligned}
\sum_{n \in N_{1 j}}[ & \left(\frac{\rho_{n}}{2} \sum_{n \in N} \rho_{n}-1\right) \sum_{j \in J} \theta_{1 j}^{D_{1}} m_{1 j}^{*}+\left(\frac{\beta_{n}}{\eta_{1 j}} \sum_{n \in N_{1 j}} \beta_{n}-1\right) m_{1 j}^{*}+\left(\frac{v_{n}}{2} \sum_{n \in N} \rho_{n}+d\right) \sum_{j \in J} \theta_{2 i}^{D_{2}} m_{2 i}^{*} \\
& \left.-\left(\frac{\gamma_{n}}{\eta_{2 i}} \sum_{n \in N_{2 i}^{D_{2}}} \beta_{n}-d\right) m_{2 i}^{*}+\bar{\alpha}_{1 n}-c_{1}-T C_{1 j}-T C_{1 j n}+d\left(c_{2}+T C_{2 i}+T C_{2 i n}\right)\right] \\
& -\left(\left|N_{1 j}^{D_{1}}\right|+2 \lambda_{R_{1 j}} \sum_{n \in N_{1 j}} \sigma_{1 n}^{2}\right) m_{1 j}^{*}=0, \quad \forall j \in J, \\
\sum_{n \in N_{2 i}^{D_{2}}}[ & \left(\frac{\rho_{n}}{2} \sum_{n \in N} \rho_{n}-1\right) \sum_{i \in I} \theta_{2 i}^{D_{2}} m_{2 i}^{*}+\left(\frac{\beta_{n}}{\eta_{2 i}} \sum_{n \in N_{2 i}^{D_{2}}} \beta_{n}-1\right) m_{2 i}^{*}+\left(\frac{v_{n}}{2} \sum_{n \in N} \rho_{n}+d\right) \sum_{j \in J} \theta_{1 j}^{D_{1}} m_{1 j}^{*} \\
& \left.-\left(\frac{\gamma_{n}}{\eta_{1 j}} \sum_{n \in N_{1 j}} \beta_{n}-d\right) m_{1 j}^{*}+\bar{\alpha}_{2 n}-c_{2}-T C_{2 i}-T C_{2 i n}+d\left(c_{1}+T C_{1 j}+T C_{1 j n}\right)\right] \\
& -\left(\left|N_{2 i}^{D_{2}}\right|+2 \lambda_{R_{2 i}} \sum_{n \in N_{2 i}^{D_{2}}} \sigma_{2 n}^{2}\right) m_{2 i}^{*}=0, \quad \forall i \in I .
\end{aligned}
$$

Afterwards, other tactical decisions, that is, wholesale prices, service levels, and advertising expenditures are achieved as follows:

$$
\begin{gathered}
w_{1}^{*}=\sum_{j \in J} \theta_{1 j} m_{1 j}^{*}+c_{1}, \\
w_{2}^{*}=\sum_{i \in I} \theta_{2 i}^{D_{2}} m_{2 i}^{*}+c_{2}, \\
a_{1}^{*}=\left(\left(\frac{1}{2} \sum_{n \in N} \rho_{n}\right) \sum_{j \in J} \theta_{1 j} m_{1 j}^{*}\right)^{2}, \\
a_{2}^{*}=\left(\left(\frac{1}{2} \sum_{n \in N} \rho_{n}\right) \sum_{j \in J} \theta_{2 i}^{D_{2}} m_{2 i}^{*}\right)^{2}, \\
s_{1 j}^{*}=\left(\frac{1}{\eta_{1 j}} \sum_{n \in N_{1 j}} \beta_{n}\right) m_{1 j}^{*}, \quad \forall j \in J, \\
s_{2 i}^{*}=\left(\frac{1}{\eta_{2 i}} \sum_{n \in N_{2 i}^{D_{2}}} \beta_{n}\right) m_{2 i}^{*}, \quad i \in I,
\end{gathered}
$$


where

$$
\begin{gathered}
\theta_{1 j}=\frac{\left(\left|N_{1 j}\right|+2 \lambda_{R_{1 j}} \sum_{n \in N_{1 j}} \sigma_{1 n}^{2}\right)}{\left(|N|+2 \lambda_{M_{1}} \sum_{n \in N} \sigma_{1 n}^{2}\right)}, \\
\theta_{2 i}^{D_{2}}=\frac{\left(\left|N_{2 i}^{D_{2}}\right|+2 \lambda_{R_{2 i}} \sum_{n \in N_{2 i}^{D_{2}}} \sigma_{2 n}^{2}\right)}{\left(|N|+2 \lambda_{M_{2}} \sum_{n \in N} \sigma_{2 n}^{2}\right)} .
\end{gathered}
$$

Proofs of all propositions are provided in Appendix. From (4.15) and (4.16), it follows that $\theta_{1 j}$ and $\theta_{2 i}^{D_{2}}$ are relative margin coefficients which determine profit margin shares among $S^{\prime} C^{\prime}$ participants. These coefficients depend on participants' risk sensitivity, number, and uncertainty of markets. Selected retailer for distributing products will withdraw from all markets if his profit margin is not positive, and that SC design will not be practicable. Therefore, in each feasible SCs' configuration, if markets are assigned to retailers $i$ and $j$ (i.e., $\left.N_{1 j}, N_{2 i}^{D_{2}} \neq \varnothing\right)$, it is needed to have $m_{1 j}^{*}, m_{2 i}^{*}>0$. Otherwise, that is, $N_{1 j}=\varnothing\left(N_{2 i}^{D_{2}} \neq \varnothing\right)$, it follows from (4.14) that $m_{1 \mathrm{j}}^{*}=0\left(m_{2 \mathrm{i}}^{*}=0\right)$. It is obvious form (4.15)-(4.18) that wholesale price and advertising expenditure of each manufacturer rise as profit margins of his retailers increase; nevertheless, these relationships also depend on retailers' relative margin coefficients. Moreover, according to (4.19) and (4.20), the higher the profit margin of each retailer, the higher offered service level will be. Outputs and utility functions of SC's participants regarding optimal tactical decisions of Proposition 4.1 are presented through the following proposition.

Proposition 4.2. If $B_{1 j}>0$, for all $j \in J, B_{2 i}^{D_{2}}>0$, for all $i \in I$, and $A_{M_{1}}, A_{M_{2}}>0$, then optimal expected demand and optimal utility of SCs' participants are as follows:

$$
\begin{gathered}
Q_{1 j}^{D_{2}^{*}}=\left(\left|N_{1 j}\right|+2 \lambda_{R_{1 j}} \sum_{n \in N_{1 j}} \sigma_{1 n}^{2}\right) m_{1 j}^{*}, \quad \forall j \in J, \\
Q_{2 i}^{D_{2}^{*}}=\left(\left|N_{2 i}^{D_{2}}\right|+2 \lambda_{R_{1 j}} \sum_{n \in N_{2 i}^{D_{2}}} \sigma_{2 n}^{2}\right) m_{2 i}^{*}, \quad \forall i \in I, \\
\sum_{j \in J} Q_{1 j}^{D_{2}^{*}}=\left(|N|+2 \lambda_{M_{1}} \sum_{n \in N} \sigma_{1 n}^{2}\right)\left(w_{1}^{*}-c_{1}\right), \\
\sum_{i \in I} Q_{2 i}^{D_{2}^{*}}=\left(|N|+2 \lambda_{M_{2}} \sum_{n \in N} \sigma_{2 n}^{2}\right)\left(w_{2}^{*}-c_{2}\right), \\
u_{R_{1 j}}\left(\tilde{\pi}_{R_{1 j}}^{D^{*}}\right)=m_{1 j}^{*} B_{1 j}, \quad \forall j \in J, \\
u_{R_{1 j}}\left(\tilde{\pi}_{R_{1 j}}^{D_{2}^{*}}\right)=m_{1 j}^{*} B_{1 j}^{D_{1}}, \quad \forall j \in J, \\
u_{M_{k}}\left(\tilde{\pi}_{P_{2}}^{D_{2}^{*}}\right)=\left(w_{k}^{*}-c_{k}\right)^{2} A_{M_{k}}, \quad \forall k=1,2 .
\end{gathered}
$$




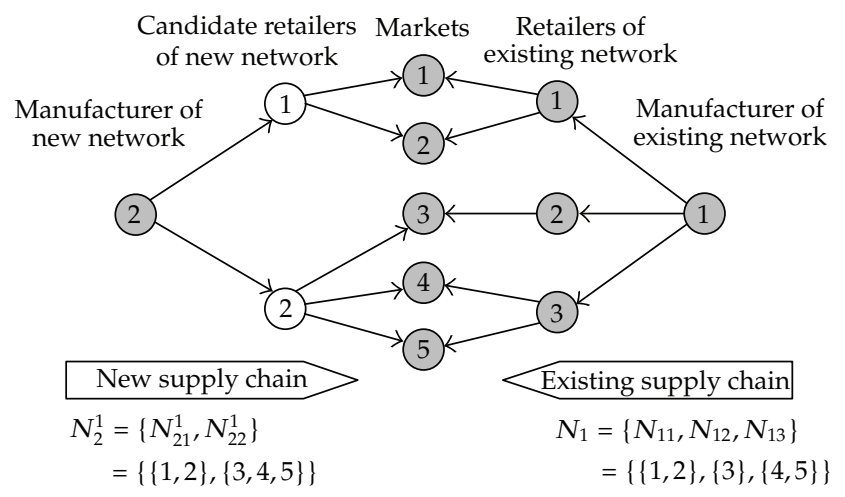

Figure 2: An example of SCs configuration design and their representations.

The conditions $B_{1 j}>0$, for all $j \in J, B_{2 \mathrm{i}}^{D_{2}}>0$, for all $i \in I$, and $A_{M_{1}}, A_{M_{2}}>0$ guarantee that the tactical strategies in Proposition 4.1 are optimal in the equilibrium state. Furthermore, it follows from (4.26)-(4.28) that these conditions bring about positive utility for retailers and manufacturers, respectively. Consequently, similar to [30-32,53], we assume that $A_{M_{1}}, A_{M_{2}}>0$ throughout the paper. These assumptions state that markets' sensitivity to advertisement should not be too high which causes manufacturers to increase their advertising expenditure, inordinately. On the other hand, we assume that $B_{1 j}>0$, for all $j \in$ $J$ and $B_{2 i}^{D_{2}}>0$, for all $i \in I$ all through the paper which imply that service level investment should not be too inexpensive $[3,35,38]$.

\subsection{The Optimal Strategic Decisions}

Retailers of an SC vary according to their geographical locations, transportation costs among them and manufacturer, covered markets, and service level efficiency, as well as their sensitivity to risk. Selecting appropriate retailer for supplying markets regarding these factors improves competitive advantage of product in the markets and increases manufacturer's profit. Configuration of distribution network to cover markets is a strategic decision that involves long-term contracts with retailers. We assume that configuration designs of SC and markets that each candidate retailer is able to cover are known to the manufacturer as a set of possible scenarios. Considering the optimal tactical decisions regarding service level, transfer price, and marketing expenditure, manufacturer of the new SC has to decide how to configure his distribution network, that is, which of the candidate retailers should be selected to cover overall markets in order to maximize utility of the network.

For example, assume that the manufacturer of the new SC considers two independent retailers in order to make products available to five intended markets. He evaluates three distinctive scenarios of distribution network design. In scenario one, the manufacturer engages both retailers. As demonstrated in Figure 2, the territory of retailer one is limited to markets 1 and 2, while retailer 2 covers other markets. Scenario one can also be represented by $N_{2}^{1}=\left\{N_{21}^{1}, N_{22}^{1}\right\}=\{\{1,2\},\{3,4,5\}\}$. Two other scenarios are related to employing a single retailer for markets, that is, $N_{2}^{2}=\{\{1,2,3,4,5\},\{\}\}$ and $N_{2}^{3}=\{\{\},\{1,2,3,4,5\}\}$. Regarding optimal value of tactical decisions in Proposition 4.1, now the manufacturer is able to evaluate the utility of each possible scenario of distribution design. 


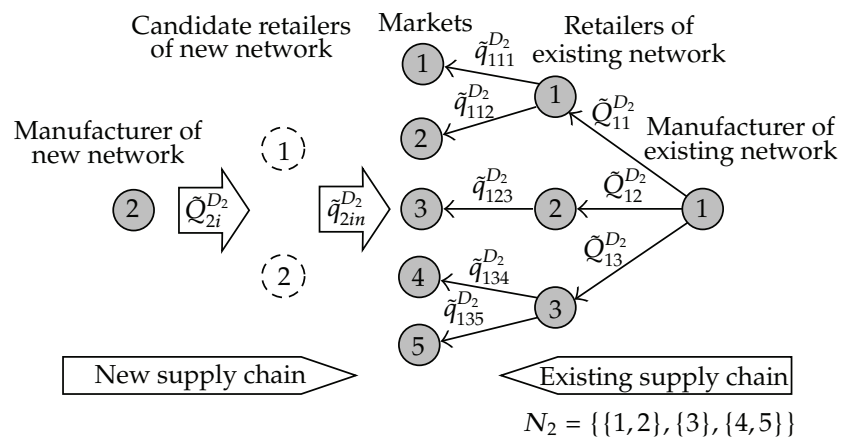

Figure 3: Structure of the existing and new SC networks in the numerical example.

Table 1: Markets data in the numerical example.

\begin{tabular}{ccccccccc}
\hline$n$ & $\beta_{n}$ & $\gamma_{n}$ & $\rho_{n}$ & $v_{n}$ & $\bar{\alpha}_{1 n}$ & $\sigma_{1 n}$ & $\bar{\alpha}_{2 n}$ & $\sigma_{2 n}$ \\
\hline 1 & 1 & 0.6 & 0.2 & -0.5 & 10 & 2 & 20 & 4 \\
2 & 1.5 & 0.8 & 0.5 & -0.8 & 15 & 4 & 15 & 2 \\
3 & 0.9 & 0.7 & 0.7 & -0.1 & 20 & 4 & 10 & 2 \\
4 & 1.1 & 0.5 & 0.4 & -0.3 & 15 & 2 & 15 & 4 \\
5 & 1.2 & 0.4 & 0.6 & -0.4 & 10 & 2 & 20 & 4 \\
\hline
\end{tabular}

\section{Numerical Results and Discussion}

In this Section, we use the scenario evaluation method for a numerical example and provide a discussion of the corresponding results. Section 5.1 is dedicated to the numerical example and the results of the scenario evaluation. In Section 5.2, the sensitivity analysis of the scenarios in the context of the example is investigated.

\subsection{Numerical Example}

Example 5.1. Our numerical example comprises two competitive networks; the existing network has three active retailers with fixed distribution structure, and the new network has two potential retailers. Two SCs compete for five distinctive markets as depicted in Figure 3.

We assume the default values of parameters

$$
c_{1}=c_{2}=10, \quad \lambda_{M_{1}}=0.2, \quad \lambda_{\mathrm{M}_{2}}=0.2 \text {. }
$$

Corresponding data to the markets, the existing SC, and new SC are listed in Tables 1, 2, and 3 , respectively.

Assume that the manufacturer of new SC encounters three scenarios of distribution deign which can be represented by $N_{2}^{1}=\{\{1,2\},\{3,4,5\}\}, N_{2}^{2}=\{\{1,2,3,4,5\},\{\}\}$, and $N_{2}^{3}=$ $\{\{\},\{1,2,3,4,5\}\}$. From Table 4, we find that scenario two has a higher expected profit and utility for the manufacturer; however, magnitudes of utility differences between scenarios two and three are not considerable. Table 5 gives the detailed information concerning optimal 
Table 2: Existing SC data in the numerical example.

\begin{tabular}{ccccccccc}
\hline$j$ & $\eta_{1 j}$ & $\lambda_{1 j}$ & $T C_{1 j}$ & $T C_{1 j 1}$ & $T C_{1 j 2}$ & $T C_{1 j 3}$ & $T C_{1 j 4}$ & $T C_{1 j 5}$ \\
\hline 1 & 5 & 0.1 & 1 & 1 & 1 & 2 & 3 & 4 \\
2 & 5 & 0.2 & 1.5 & 3 & 2 & 1 & 2 & 3 \\
3 & 5 & 0.1 & 2 & 4 & 3 & 2 & 1 & 1 \\
\hline
\end{tabular}

Table 3: New SC data in the numerical example.

\begin{tabular}{ccccccccc}
\hline$i$ & $\eta_{2 i}$ & $\lambda_{2 i}$ & $T C_{2 i}$ & $T C_{2 i 1}$ & $T C_{2 i 2}$ & $T C_{2 i 3}$ & $T C_{2 i 4}$ & $T C_{2 i 5}$ \\
\hline 1 & 5 & 0.1 & 1 & 1 & 1 & 1 & 4 & 4 \\
2 & 5 & 0.1 & 1 & 4 & 4 & 1 & 1 & 1 \\
\hline
\end{tabular}

Table 4: Optimal utility of new SC's distribution design under each scenario $(d=0.9)$.

\begin{tabular}{|c|c|c|c|}
\hline & $\begin{array}{c}\text { Scenario } 1 \\
N_{2}^{1}= \\
\{\{1,2\},\{3,4,5\}\}\end{array}$ & $\begin{array}{c}\text { Scenario } 2 \\
N_{2}^{2}= \\
\{\{1,2,3,4,5\},\{\}\}\end{array}$ & $\begin{array}{c}\text { Scenario 3 } \\
N_{2}^{3}= \\
\{\{\},\{1,2,3,4,5\}\}\end{array}$ \\
\hline Expected profit, $E\left(\widetilde{\pi}_{M_{2}}\right)$ & 230.40 & 293.85 & 288.91 \\
\hline $\begin{array}{l}\text { Utility of network design } \\
\text { scenario for manufacturer 2, } \\
u\left(\widetilde{\pi}_{M_{2}}\right)\end{array}$ & 131.00 & 167.07 & 164.27 \\
\hline
\end{tabular}

Table 5: Optimal values of the supply chain networks in scenario two $(d=0.9)$.

\begin{tabular}{lcccc}
\hline Variables and characteristics & \multicolumn{2}{c}{ Existing network } & \multicolumn{2}{c}{ New network } \\
\hline Supply chain network design & \multicolumn{2}{c}{$N_{1}^{1}=\{\{1,2\},\{3\},\{4,5\}\}$} & $N_{2}^{2}=\{\{1,2,3,4,5\},\{\}\}$ \\
\hline $\begin{array}{l}\text { Utility of network design } \\
\text { scenario for the manufacturer }\end{array}$ & $u_{M_{1}}\left(\tilde{\pi}_{M_{1}}^{*}\right)$ & 95.403 & $u_{M_{2}}\left(\tilde{\pi}_{M_{2}}^{*}\right)$ & 167.07 \\
$\begin{array}{l}\text { Expected profit of the } \\
\text { manufacturers in the scenario }\end{array}$ & $E\left(\tilde{\pi}_{M_{1}}^{*}\right)$ & 163.33 & $E\left(\tilde{\pi}_{M_{2}}^{*}\right)$ & 293.85 \\
$\begin{array}{l}\text { Utility and expected profit of } \\
\text { retailers in the scenario }\end{array}$ & $u_{R_{11}}\left(\tilde{\pi}_{R_{11}}^{*}\right), E\left(\tilde{\pi}_{R_{11}}^{*}\right)$ & $33.751,53.751$ & $u_{R_{12}}\left(\tilde{\pi}_{R_{12}}^{*}\right), E\left(\tilde{\pi}_{R_{12}}^{*}\right)$ & 238.030, \\
& $u_{R_{21}}\left(\tilde{\pi}_{R_{11}}^{*}\right), E\left(\tilde{\pi}_{R_{21}}^{*}\right)$ & $26.920,47.833$ & $u_{R_{22}}\left(\tilde{\pi}_{R_{22}}^{*}\right), E\left(\tilde{\pi}_{R_{22}}^{*}\right)$ & 0,0 \\
& $u_{R_{31}}\left(\tilde{\pi}_{R_{31}}^{*}\right), E\left(\tilde{\pi}_{R_{31}}^{*}\right)$ & $108.620,146.88$ & & \\
Wholesale prices and & $w_{1}^{*}, a_{1}^{*}$ & $12.778,11.115$ & $w_{2}^{*}, a_{2}^{*}$ & $13.364,16.3$ \\
advertising expenditures & $\left(m_{11}^{*}, m_{12}^{*}, m_{13}^{*}\right)$ & $(3.162,2.557,6.916)$ & $\left(m_{21}^{*}, m_{22}^{*}\right)$ & $(5.690,0)$ \\
$\begin{array}{l}\text { Profit margins of retailers } \\
\text { Service level of retailers }\end{array}$ & $\left(s_{11}^{*}, s_{12}^{*}, s_{13}^{*}\right)$ & $(1.581,0.460,3.181)$ & $\left(s_{21}^{*}, s_{22}^{*}\right)$ & $(6.487,0)$ \\
\hline
\end{tabular}

scenario. The structure of scenario two and demand quantities of markets and retailers are illustrated in Figure 4.

\subsection{Discussion}

The previous numerical example presents the optimal scenario and equilibrium tactical decisions of two competitive SCNs. In real world competition, these decisions are affected by conservative behavior of participants. To capture these effects, we now discuss the sensitivity 


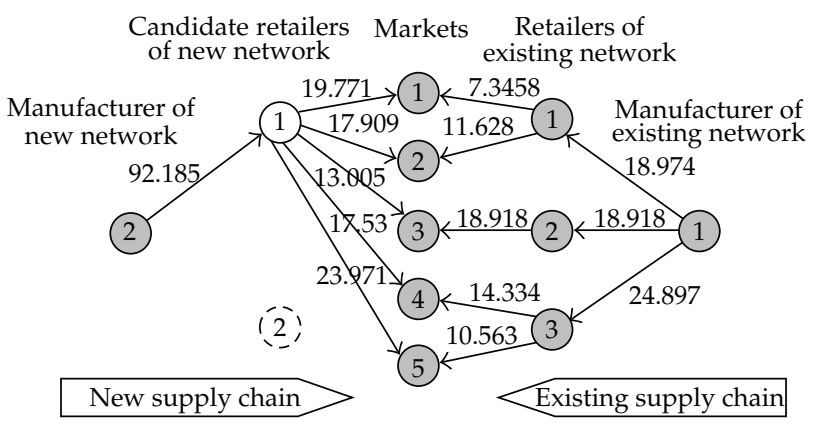

Figure 4: Supply chain networks, expected demand, and ordered quantities in scenario two (optimal scenario) of distribution design $(d=0.9)$.

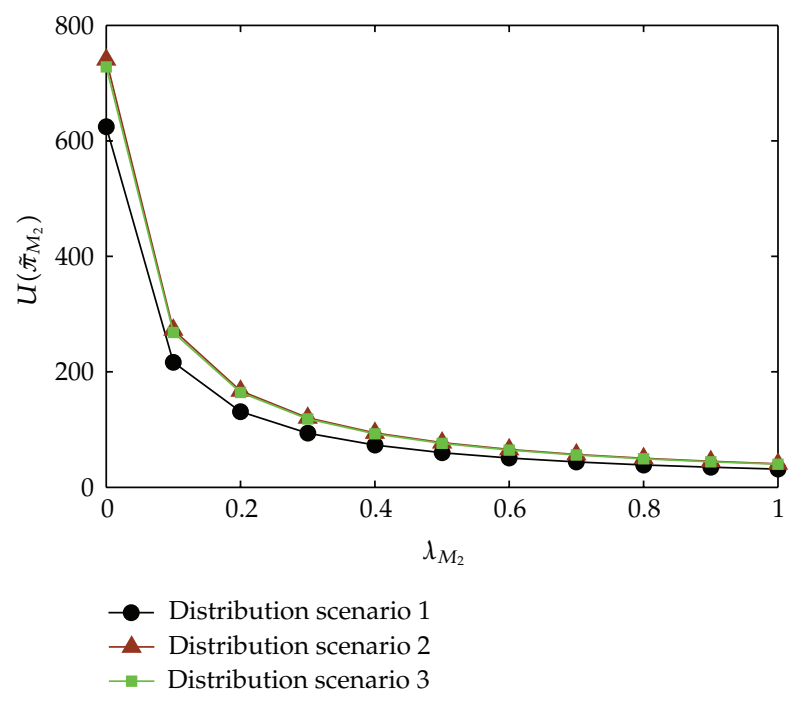

Figure 5: The utility obtained by manufacturer 2 in each scenario versus the risk sensitivity of the manufacturer.

analysis of the expected profit and the utility of each scenario of distribution network with respect to risk sensitivity of the retailers and manufacturers.

First of all, we investigate the behavior of utility of scenarios, their expected profit, and demand quantity with respect to risk sensitivity of the manufacturer in the new SC. For the above solved example, Figures 5 and 6 illustrate how utility of scenarios and expected profits of the manufacturer in the new SC depend on the risk sensitivity of the manufacturer, respectively. We know from these graphs that risk aversion behavior of the manufacturer has a negative impact on his utility from distribution scenarios and his expected profit. Nevertheless, priority of scenarios remains unchanged by conservative behavior of the manufacturer. Regarding the little difference between utilities of scenarios two and three, the manufacturer may be indifferent to the selection of one of the retailers. Likewise, as depicted in Figure 7, the expected demand quantity from SC 1 decreases as the risk sensitivity of the manufacturer increases. When it comes to the sale quantities, the dualretailer distribution scenario dominates the single-retailer distribution, as the conservative behavior of the manufacturer is intensified. 


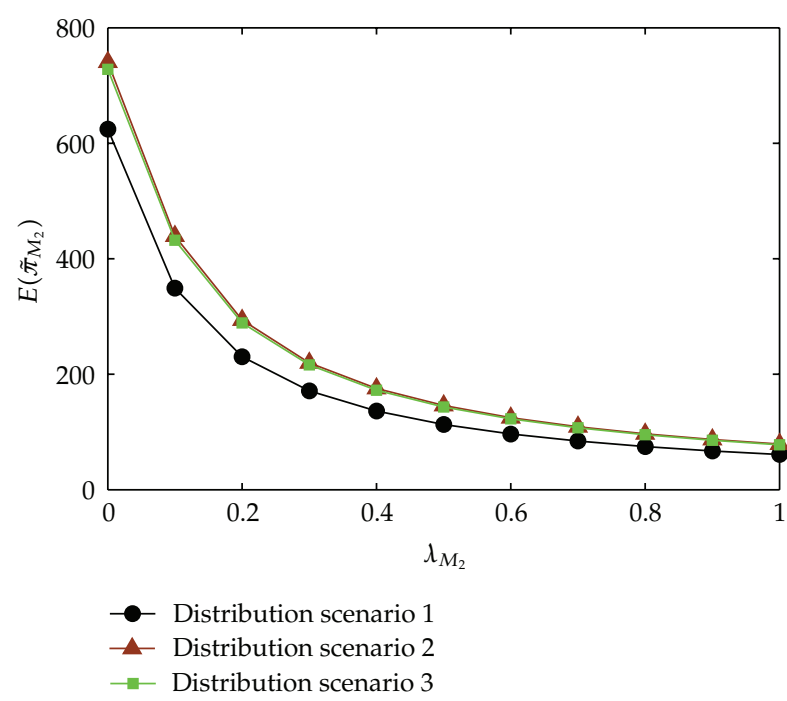

Figure 6: The expected profit of manufacturer 2 in each scenario versus the risk sensitivity of the manufacturer.

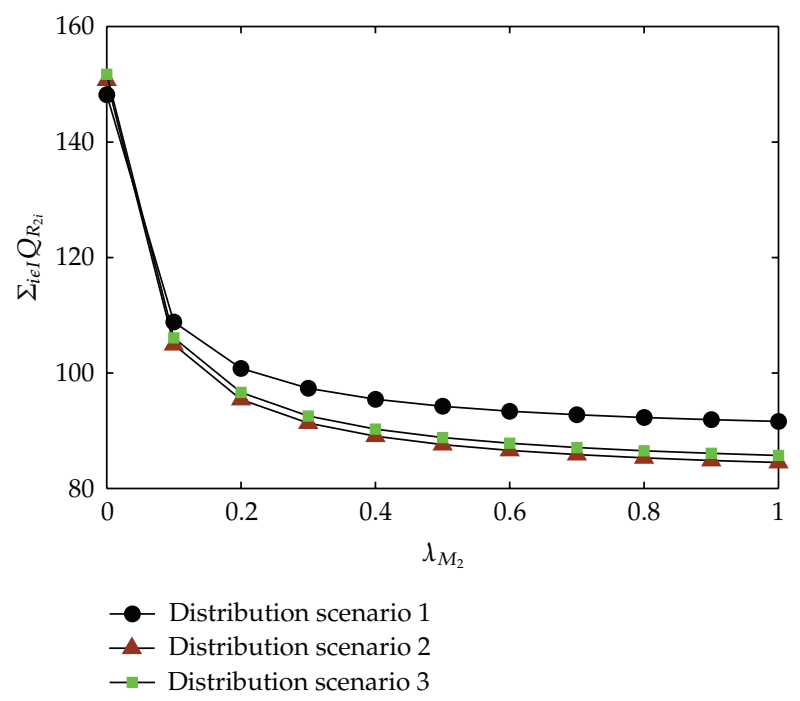

Figure 7: The expected demand quantity of manufacturer 2 in each scenario versus the risk sensitivity of the manufacturer.

Figure 8 shows that the risk sensitivity of the manufacturer in the new SC and his distribution network design have considerable impact on the utility obtained by the rival manufacturer. Specifically, when the manufacturer behaves excessively conservative, utility of the manufacturer in the existing SC shrinks. Similar conclusion is drawn from Figure 9; that is increasing risk sensitivity of the manufacturer in the existing SC reduces the utility obtained by the new SC's manufacturer.

Figures 10-13 demonstrate how the utility of the rival manufacturers changes with respect to conservative behavior of the new SC's retailers. It is obvious from the graphs 


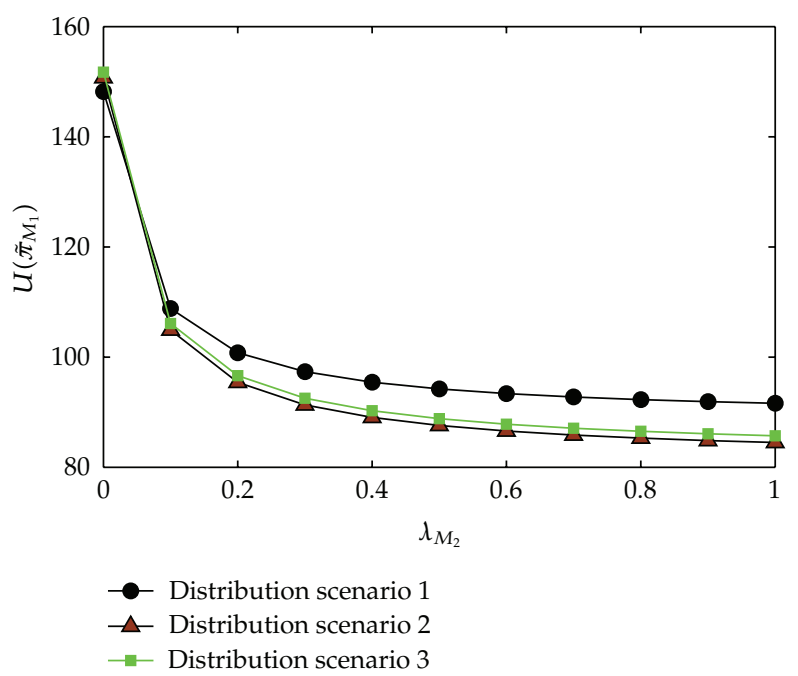

Figure 8: The utility obtained by manufacturer 1 in each scenario of SC 2 versus the risk sensitivity of manufacturer 2.

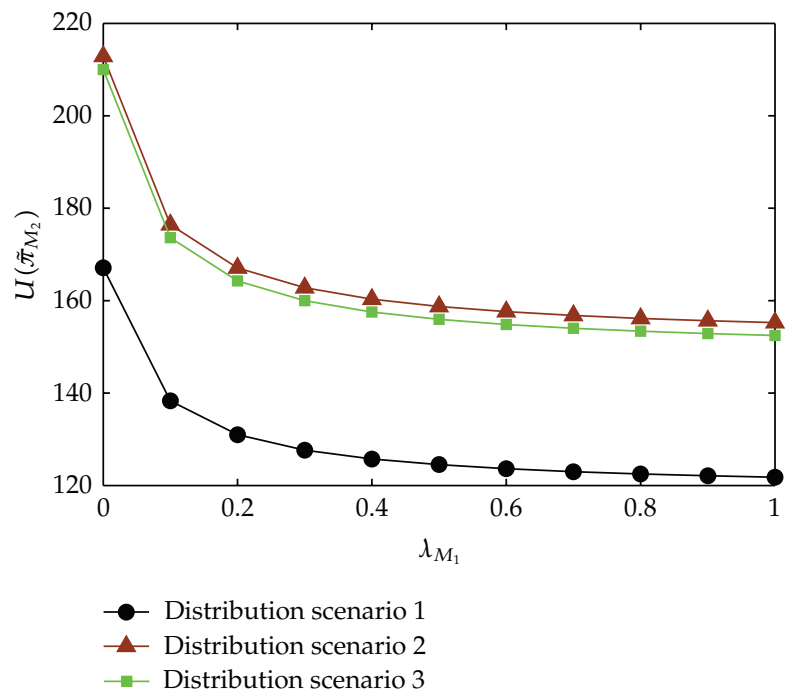

Figure 9: The utility obtained by manufacturer 2 in each scenario versus the risk sensitivity of manufacturer 1.

that risk aversion behavior of the inactive retailer (e.g., retailer 2 in distribution scenario 2) has no influence on utility of the manufacturers. Nevertheless, conservative behavior of an active retailer may have a significant effect on optimal distribution design scenario of the manufacturer. We find from Figures 10 and 12 that when one retailer monopolizes all markets (scenarios 2 and 3), his conservative behavior decreases utility of his manufacturer. However, the situation is reversed when two retailers exist (scenario 1); that is, the risk-averseness of one of the retailers boosts utility of the manufacturer. It is straightforward from Figures 11 and 13 that in all scenarios, the risk sensitivity of one retailer diminishes the utility of the rival manufacturer. 


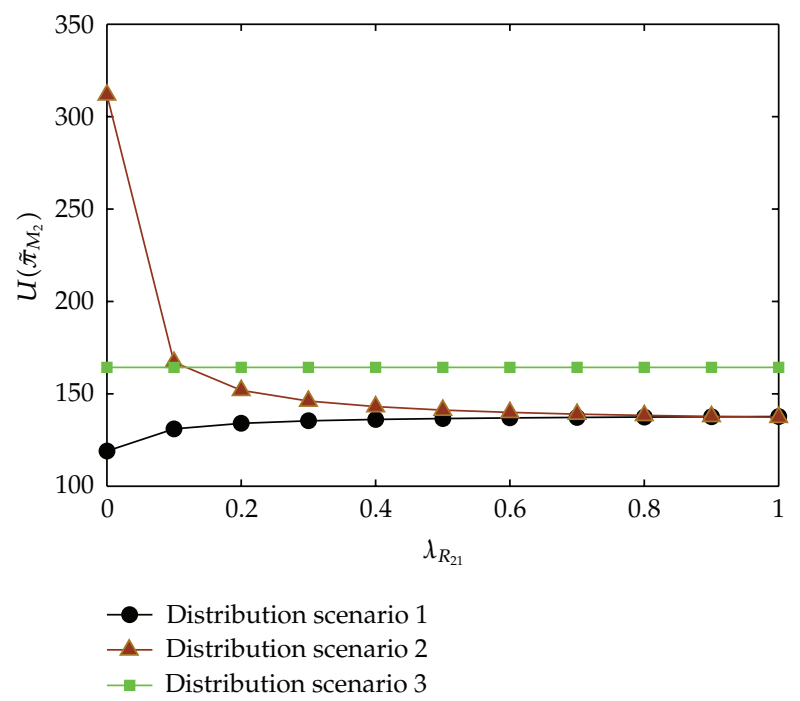

Figure 10: The utility obtained by manufacturer 2 in each scenario versus the risk sensitivity of retailer 1 in the new SC.

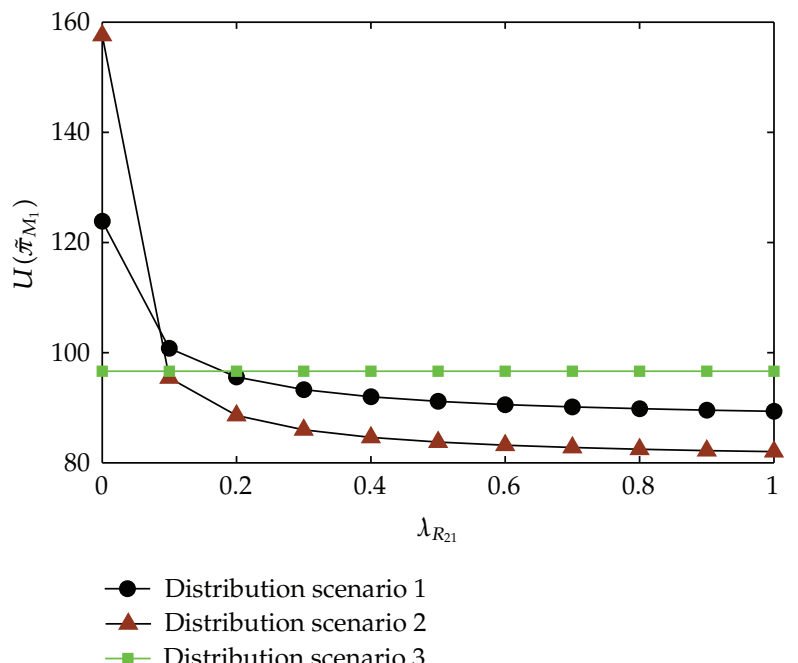

Figure 11: The utility obtained by manufacturer 1 in each scenario versus the risk sensitivity of retailer 1 in the new SC.

Now, we conclude the following managerial insights from the sensitivity analyses.

(i) Conservative behavior of the manufacturer would diminish his sale quantity, expected profit, and utility of all distribution scenarios. Conservatism sounds a reasonable behavior, if fluctuation of markets demand exerts deleterious effects on the manufacturer, for example, because of costly changes in production capacities.

(ii) Risk sensitivity of each manufacturer reduces utility of his rival manufacturer. Therefore, the manufacturers may pretend an excessive conservativeness. Since the rival may have an incentive to conceal his real CARA and show a more beneficial CARA, the manufacturer should employ a mechanism to achieve the actual risk sensitivity of his rival company and avoid overestimating. 


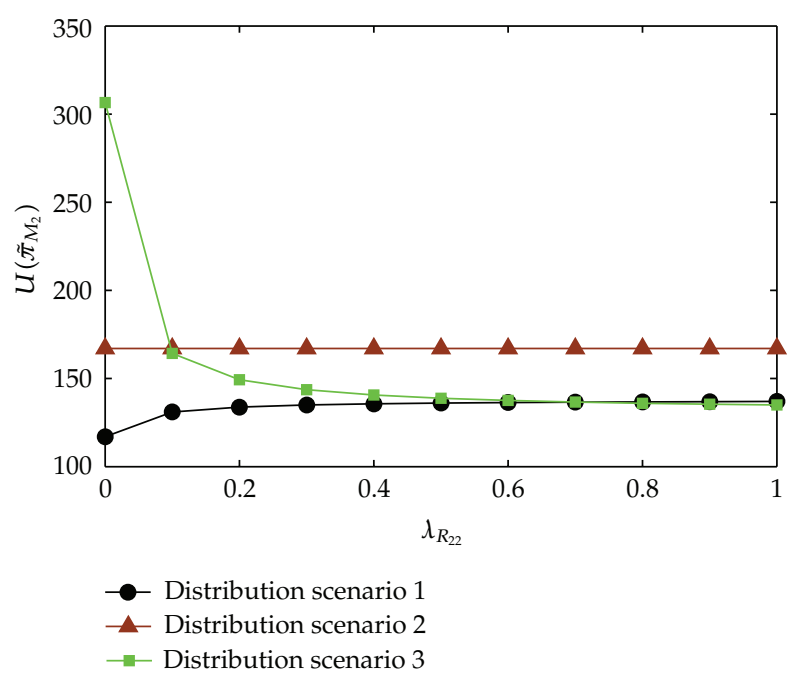

Figure 12: The utility obtained by manufacturer 2 in each scenario versus the risk sensitivity of retailer 2 in the new SC.

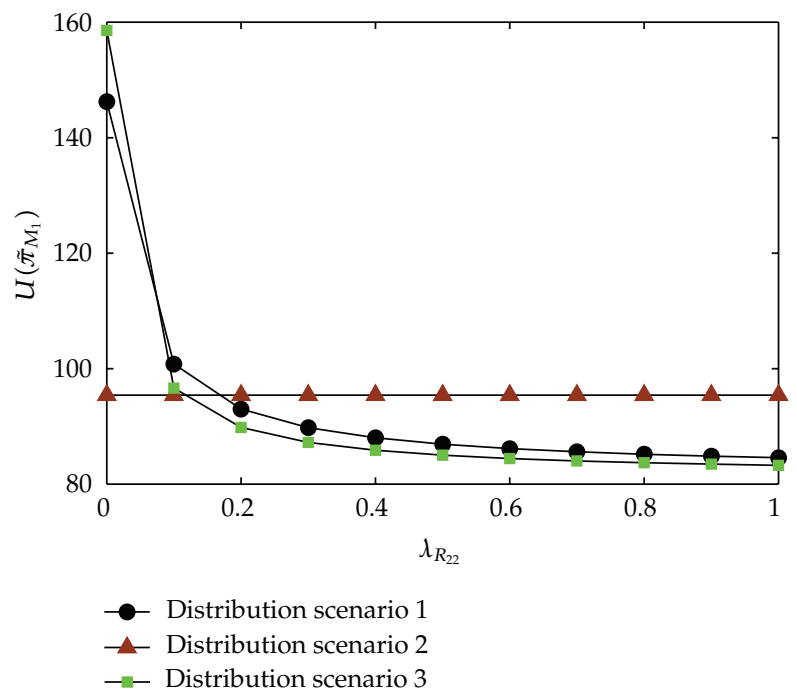

Figure 13: The utility obtained by manufacturer 1 in each scenario versus the risk sensitivity of retailer 2 in the new SC.

(iii) A candidate retailer has the added incentive to reveal low risk sensitivity to the manufacturer. Since this conduct increases the utility of distribution scenario from the manufacturer point of view, there is a higher probability for the manufacturer to contract with the retailer. Thus, the manufacturer should apply mechanism to obtain actual information concerning risk sensitivity of the candidate retailers and avoid underestimating.

\section{Conclusion}

In this paper, an integrated equilibrium model for tactical decisions in network design has been developed. We considered a decentralized supply chain network operating in markets 
under uncertain demands when there is a rival decentralized chain. The primary assumption was that two chains provide partial substitutable products to the markets, and markets' demands are affected by tactical decisions of both chains such as price, service level, and advertising expenditure. Each chain consists of one risk-averse manufacturer and a set of risk-averse retailers. The manufacturer in the new supply chain encounters a set of possible scenarios of distribution design (a set of distribution channels). In each scenario, the active retailers and a set of markets supplied by each retailer are specified.

The equilibrium values of tactical decisions were computed for each possible distribution scenario. The manufacturer is then able to choose favorable distribution design by employing scenario evaluation method. The method was implemented for an illustrative numerical example, and afterward we mainly discussed the impact of risk sensitivity of members on expected demand, profit, and utility of each distribution scenario. We realized that the risk attitude of each candidate retailer and rival manufacturer profoundly influences the utility of the distribution design scenario to the manufacturer in the new chain. Therefore, the manufacturer should use a mechanism to estimate the real risk sensitivity of the retailers and the rival manufacturer.

For future research, this model can be adopted to structuring both rival chains at the strategic level. In addition, a multiperiod problem in which the tactical problem reiterates over planning horizon as a repeated game will be very interesting. Multicriteria decisionmaking at the strategic or tactical level could also be an interesting extension of the model. Alternatively, stackelberg equilibrium could be investigated as well when the manufacturer or his retailer (retailers) has (have) the initiative in decision-making and enforces his strategy to other party (parties). Finally, this paper considers risk sensitivities of participants in the rival SC to be common knowledge for decision makers; however, in the real world competition, there is always a level of uncertainty concerning rival's behavior. Therefore, one can extend this model to take account of the rival's uncertainty.

\section{Appendix}

Proof of Proposition 4.1. It is obvious from Hessian matrices $H_{R_{1 j}}$ and $H_{R_{2 i}}^{D_{2}}$ that utility functions (4.7) and (4.8), in turn, are concave functions on $\left(m_{1 j}, s_{1 j}\right)$ and $\left(m_{2 i}, s_{2 i}\right)$, if $B_{1 j}>0$ and $B_{2 i}^{D_{2}}>0$, respectively. That is, $B_{1 j}, B_{2 i}^{\mathrm{D}_{2}}>0$ guarantee that first-order conditions (A.1)(A.4) yield optimal tactical decisions for the retailers. This first-order conditions of utility functions corresponding retailers and manufacturers, in turn, are as follows:

$$
\begin{gathered}
\frac{\partial u_{R_{1 j}}\left(\tilde{\pi}_{R_{1 j}}^{D_{2}}\right)}{\partial m_{1 j}}=\sum_{\substack{n \in N_{1 j} \\
\forall n, i \rightarrow D_{2}}} \bar{q}_{1 j n}^{D_{2}}-\left(\left|N_{1 j}\right|+2 \lambda_{R_{1 j}} \sum_{n \in N_{1 j}} \sigma_{1 n}^{2}\right) m_{1 j}=0, \quad \forall j \in J, \\
\frac{\partial u_{R_{1 j}}\left(\tilde{\pi}_{R_{1 j}}^{D_{2}}\right)}{\partial s_{1 j}}=m_{1 j} \sum_{n \in N_{1 j}} \beta_{n}-\eta_{1 j} s_{1 j}=0, \quad \forall j \in J, \\
\frac{\partial u_{R_{2 i}}\left(\tilde{\pi}_{R_{2 i}}^{D_{2}}\right)}{\partial m_{2 i}}=\sum_{\substack{n \in N_{2 i}^{D_{2}} \\
\forall n, j \rightarrow D_{1}}} \bar{q}_{2 i n}^{D_{2}}-\left(\left|N_{2 i}^{D_{2}}\right|+2 \lambda_{R_{2 i}} \sum_{n \in N_{2 i}^{D_{2}}} \sigma_{2 n}^{2}\right) m_{2 i}=0, \quad \forall i \in I,
\end{gathered}
$$




$$
\begin{gathered}
\frac{\partial u_{R_{2 i}}\left(\tilde{\pi}_{R_{2 i}}^{D_{2}}\right)}{\partial s_{2 i}}=m_{2 i} \sum_{n \in N_{2 i}^{D_{2}}} \bar{q}_{1 j n}^{D_{2}}-\eta_{2 i} s_{2 i}=0, \quad \forall \mathrm{i} \in I, \\
\frac{\partial u_{M_{1}}\left(\tilde{\pi}_{M_{1}}^{D_{2}}\right)}{\partial w_{1}}=\sum_{j \in J} \sum_{\substack{n \in N_{1 j} \\
\forall n, i \rightarrow D_{2}}} \bar{q}_{1 j n}^{D_{2}}-\left(|N|+2 \lambda_{M_{1}} \sum_{n \in N} \sigma_{1 n}^{2}\right)\left(w_{1}-c_{1}\right)=0, \\
\frac{\partial u_{M_{1}}\left(\tilde{\pi}_{M_{1}}^{D_{2}}\right)}{\partial a_{1}}=\frac{\left(w_{1}-c_{1}\right)}{2 \sqrt{a_{1}}} \sum_{n \in N} \rho_{n}-1=0, \\
\frac{\partial u_{M_{2}}\left(\tilde{\pi}_{M_{2}}^{D_{2}}\right)}{\partial w_{2}}= \\
\sum_{i \in I} \sum_{n \in N_{2 i}^{D_{1}}} \bar{q}_{2 i n}^{D_{2}}-\left(|N|+2 \lambda_{M_{2}} \sum_{n \in N} \sigma_{2 n}^{2}\right)\left(w_{2}-c_{2}\right)=0, \\
\frac{\partial u_{M_{2}}\left(\tilde{\pi}_{M_{2}}^{D_{2}}\right)}{\partial a_{2}}=\frac{\left(w_{2}-c_{2}\right)}{2 \sqrt{a_{2}}} \sum_{n \in N} \rho_{n}-1=0 .
\end{gathered}
$$

From Hessian matrix $H_{M_{1}}$ of utility function (4.9) as well as (A.6), we know that $u_{M_{1}}\left(\tilde{\pi}_{M_{1}}^{D_{2}}\right)$ is jointly concave on $\left(w_{1}, a_{1}\right)$, if $A_{M_{1}}>0$. Similarly, From Hessian matrix $H_{\mathrm{M}_{2}}$ and (A.8), it follows that $u_{M_{2}}\left(\tilde{\pi}_{M_{2}}^{D_{2}}\right)$ is a concave function on $\left(w_{2}, a_{2}\right)$, if $A_{M_{2}}>0$. Consequently, $A_{M_{1}}, A_{M_{2}}>0$ assure that first-order conditions (A.5)-(A.8) result in optimal tactical decisions for the manufacturers. The sum of (A.1) for all retailers $(j \in J)$ and the sum of (A.3) for all corresponding retailers $(i \in I)$, in turn, yield

$$
\begin{gathered}
\sum_{j \in J} \sum_{\substack{n \in N_{1 j} \\
\forall n, i \rightarrow D_{2}}} \bar{q}_{1 j n}^{D_{2}}-\sum_{j \in J}\left(\left|N_{1 j}\right|+2 \lambda_{R_{1 j}} \sum_{n \in N_{1 j}} \sigma_{1 n}^{2}\right) m_{1 j}=0 \\
\sum_{\substack{\forall i \in I \\
\forall n, j \rightarrow N_{1}}} \sum_{\substack{n \in D_{2} \\
\forall n, j i n}} \bar{q}_{2 i n}^{D_{2}}-\sum_{\forall i \in I}\left(\left|N_{2 i}^{D_{2}}\right|+2 \lambda_{R_{2 i}} \sum_{n \in N_{2 i}^{D_{2}}} \sigma_{2 n}^{2}\right) m_{2 i}=0 .
\end{gathered}
$$

Subtracting (A.5) from (A.9) and (A.7) from (A.10), in turn, yield

$$
\begin{gathered}
w_{1}=\frac{\sum_{j \in J}\left(\left|N_{1 j}\right|+2 \lambda_{R_{1 j}} \sum_{n \in N_{1 j}} \sigma_{1 n}^{2}\right) m_{1 j}}{\left(|N|+2 \lambda_{M_{1}} \sum_{n \in N} \sigma_{1 n}^{2}\right)}+c_{1}, \\
w_{2}=\frac{\sum_{\forall i \in I}\left(\left|N_{2 i}^{D_{2}}\right|+2 \lambda_{R_{2 i}} \sum_{n \in N_{2 i}^{D_{2}}} \sigma_{2 n}^{2}\right) m_{2 \mathrm{i}}}{\left(|N|+2 \lambda_{\mathrm{M}_{2}} \sum_{n \in N} \sigma_{2 n}^{2}\right)}+c_{2} .
\end{gathered}
$$


Therefore, (4.15) and (4.16) follow. From (A.6) and (A.8) along with (A.11), optimal advertising expenditures (4.17) and (4.18) are straightforward. Furthermore, we can obtain optimal service levels (4.19) and (4.20) from (A.2) and (A.4). Finally, inserting (4.15)-(4.20) into first-order conditions (A.1) and (A.3), after some manipulations, gives linear system of (4.14) and (14). Thus, Proposition 4.1 follows.

Proof of Proposition 4.2. Optimal quantities (4.22)-(4.25) immediately follow from (A.1), (A.3), (A.5), and (A.7), respectively. Inserting optimal quantity (4.22) and optimal service level (4.19) into (4.7), we have

$$
u_{R_{1 j}}\left(\tilde{\pi}_{R_{1 j}}^{D_{2}^{*}}\right)=m_{1 j}^{*^{2}}\left(\left|N_{1 j}\right|+2 \lambda_{R_{1 j}} \sum_{n \in N_{1 j}} \sigma_{1 n}^{2}\right)-\frac{m_{1 j}^{*^{2}}}{2 \eta_{1 j}}\left(\sum_{n \in N_{1 j}} \beta_{n}\right)-\lambda_{R_{1 j}} m_{1 j}^{*^{2}} \sum_{n \in N_{1 j}} \sigma_{1 n}^{2}, \quad \forall j \in J .
$$

Thus, the optimal utility of retailer $j$ is $u_{R_{1 j}}\left(\widetilde{\pi}_{R_{1 j}^{*}}^{D_{1 j}}\right)=m_{1 j}^{*^{2}} B_{1 j}$. Similarly, we can show optimal utility (4.27) for retailer $i$ in the new SC. Putting optimal quantity (4.24) and optimal advertising expenditure from (A.6) in utility function (4.9), we obtain

$$
\begin{aligned}
u_{M_{1}}\left(\tilde{\pi}_{M_{1}}^{D_{2}^{*}}\right)= & \left(w_{1}^{*}-c_{1}\right)^{2}\left(|N|+2 \lambda_{M_{1}} \sum_{n \in N} \sigma_{1 n}^{2}\right)-\left(\frac{1}{2} \sum_{n \in N} \rho_{n}\right)^{2}\left(w_{1}^{*}-c_{1}\right)^{2} \\
& -\lambda_{M_{1}}\left(w_{1}-c_{1}\right)^{2} \sum_{n \in N} \sigma_{1 n}^{2} .
\end{aligned}
$$

Therefore, the optimal utility of manufacturer 1 is $u_{M_{1}}\left(\tilde{\pi}_{M_{1}}^{D_{2}}\right)=\left(w_{k}^{*}-c_{k}\right)^{2} A_{M_{1}}$. Optimal utility of manufacturer in the new SC is straightforward in a similar manner, and Proposition 4.2 follows.

\section{References}

[1] K. Kogan and C. S. Tapiero, Supply Chain Games: Operations Management and Risk Valuation, International Series in Operations Research \& Management Science, 113, Springer, New York, NY, USA, 2007.

[2] C. Chandra and J. Grabis, Supply Chain Configuration: Concepts, Solutions and Applications, Springer, New York, NY, USA, 2007.

[3] T. Xiao and D. Yang, "Price and service competition of supply chains with risk-averse retailers under demand uncertainty," International Journal of Production Economics, vol. 114, no. 1, pp. 187-200, 2008.

[4] S. Rezapour and R. Z. Farahani, "Strategic design of competing centralized supply chain networks for markets with deterministic demands," Advances in Engineering Software, vol. 41, no. 5, pp. 810822, 2010.

[5] T. Boyaci and G. Gallego, "Supply chain coordination in a market with customer service competition," Production and Operations Management, vol. 13, no. 1, pp. 3-22, 2004.

[6] A. Jain, "Value of capacity pooling in supply chains with heterogeneous customers," European Journal of Operational Research, vol. 177, no. 1, pp. 239-260, 2007.

[7] D. Zhang, "A network economic model for supply chain versus supply chain competition," Omega, vol. 34, no. 3, pp. 283-295, 2006.

[8] S. Chopra and P. Meindl, Supply Chain Management, Strategy, Planning, and Operation, Prince Hall, Long Branch, NJ, USA, 2007.

[9] D. Simchi-Levi and P. Kaminsky, Designing and Managing the Supply Chain, McGraw-Hill/Irwin, New York, NY, USA, 2003. 
[10] E. N. Barron, Game Theory: An Introduction, Wiley-Interscience, Hoboken, NJ, USA, 2008.

[11] A. A. Tsay, "Risk sensitivity in distribution channel partnerships: implications for manufacturer return policies," Journal of Retailing, vol. 78, no. 2, pp. 147-160, 2002.

[12] D. Selz and S. Klein, "Emerging electronic intermediaries-the case of the automotive industry," in Proceedings of 10th Bled EC Conference, pp. 316-336, Bled, Slovenia, 1997.

[13] A. A. Tsay and N. Agrawal, "Modeling conflict and coordination in multi-channel distribution systems: a review," in Supply Chain Management in the E-Business Era, D. Simchi-Levi, D. Wu, and M. Shen, Eds., Kluwer Academic Publishers, Boston, Mass, USA, 2004.

[14] C. A. Ingene and M. E. Parry, "Coordination and manufacturer profit maximization: the multiple retailer channel," Journal of Retailing, vol. 71, no. 2, pp. 129-151, 1995.

[15] S. Netessine and N. Rudi, "Supply chain structures on the internet: marketing-operations coordination under drop-shipping," Tech. Rep., The Wharton School, University of Pennsylvania, 2001.

[16] J. C. Fransoo, M. J. F. Wouters, and T. G. de Kok, “Multi-echelon multi-company inventory planning with limited information exchange," Journal of the Operational Research Society, vol. 52, no. 7, pp. 830838, 2001.

[17] F. Chen, A. Federgruen, and Y. S. Zheng, "Coordination mechanisms for a distribution system with one supplier and multiple retailers," Management Science, vol. 47, no. 5, pp. 693-708, 2001.

[18] Q. Meng, Y. Huang, and R. L. Cheu, "Competitive facility location on decentralized supply chains," European Journal of Operational Research, vol. 196, no. 2, pp. 487-499, 2009.

[19] H. Kurata, D. Q. Yao, and J. J. Liu, "Pricing policies under direct vs. indirect channel competition and national vs. store brand competition," European Journal of Operational Research, vol. 180, no. 1, pp. 262-281, 2007.

[20] P. L. Abad, "Supplier pricing and lot sizing when demand is price sensitive," European Journal of Operational Research, vol. 78, no. 3, pp. 334-354, 1994.

[21] W. J. Lee, "Determining order quantity and selling price by geometric programming," Decision Sciences, vol. 24, no. 1, pp. 76-87, 1993.

[22] W. J. Lee and D. Kim, "Optimal and heuristic decision strategies for integrated product and marketing planning," Decision Sciences, vol. 24, no. 6, pp. 1203-1213, 1993.

[23] H. Jung and C. M. Klein, "Optimal inventory policies under decreasing cost functions via geometric programming," European Journal of Operational Research, vol. 132, no. 3, pp. 628-642, 2001.

[24] H. Jung and C. M. Klein, "Optimal inventory policies for an economic order quantity model with decreasing cost functions," European Journal of Operational Research, vol. 165, no. 1, pp. 108-126, 2005.

[25] J. R. Freeland, "Coordination strategies for production and marketing in a functionally decentralized firm," AIIE Transactions, vol. 12, no. 2, pp. 126-132, 1980.

[26] S. J. Sadjadi, M. Oroujee, and M. B. Aryanezhad, "Optimal production and marketing planning," Computational Optimization and Applications, vol. 30, no. 2, pp. 195-203, 2005.

[27] M. Esmaeili and P. Zeephongsekul, "Seller-buyer models of supply chain management with an asymmetric information structure," International Journal of Production Economics, vol. 123, no. 1, pp. 146-154, 2010.

[28] M. Esmaeili, M. B. Aryanezhad, and P. Zeephongsekul, "A game theory approach in seller-buyer supply chain," European Journal of Operational Research, vol. 195, no. 2, pp. 442-448, 2009.

[29] P. Koltler and K. L. Keller, Marketing Management, Pearson Prentice Hall, Upper Saddle River, NJ, USA, 2006.

[30] F. Gasmi, J. J. Laffont, and Q. Vuong, "Econometric analysis of collusive behavior in soft-drink market," Journal of Economic Behavior and Organization, vol. 1, no. 2, pp. 277-311, 1992.

[31] V. Kadiyali, "Entry, its deterrence, and its accommodation: a study of the U.S. photographic film industry," RAND Journal of Economics, vol. 27, no. 3, pp. 452-478, 1996.

[32] W. P. Putsis and R. Dhar, "Category expenditure, promotion and competitive market interactions: can promotions really expand the pie?" Tech. Rep., London Business School/Yale School of Management, London, UK, 1999.

[33] P. S. H. Leeflang, "Modeling competitive responsiveness," in Handbook of Marketing Decision Models, B. Wierenga, Ed., Springer Science, New York, NY, USA, 2008.

[34] T. Xiao and D. Yang, "Risk sharing and information revelation mechanism of a one-manufacturer and one-retailer supply chain facing an integrated competitor," European Journal of Operational Research, vol. 196, no. 3, pp. 1076-1085, 2009.

[35] A. A. Tsay and N. Agrawal, "Channel dynamics under price and service competition," Manufacturing and Service Operations Management, vol. 2, no. 4, pp. 372-391, 2000. 
[36] F. Bernstein and A. Federgruen, "Coordination mechanisms for supply chains under price and service competition," Manufacturing and Service Operations Management, vol. 9, no. 3, pp. 242-262, 2007.

[37] G. Allon and A. Federgruen, "Competition in service industries," Operations Research, vol. 55, no. 1, pp. 37-55, 2007.

[38] D. Yang, T. Xiao, and H. Shen, "Pricing, service level and lot size decisions of a supply chain with risk-averse retailers: implications to practitioners," Production Planning and Control, vol. 20, no. 4, pp. 320-331, 2009.

[39] S. A. Mirhassani, C. Lucas, G. Mitra, E. Messina, and C. A. Poojari, "Computational solution of capacity planning models under uncertainty," Parallel Computing, vol. 26, no. 5, pp. 511-538, 2000.

[40] P. Tsiakis, N. Shah, and C. C. Pantelides, "Design of multi-echelon supply chain networks under demand uncertainty," Industrial and Engineering Chemistry Research, vol. 40, no. 16, pp. 3585-3604, 2001.

[41] T. Santoso, S. Ahmed, M. Goetschalckx, and A. Shapiro, "A stochastic programming approach for supply chain network design under uncertainty," European Journal of Operational Research, vol. 167, no. 1, pp. 96-115, 2005.

[42] A. Nagurney, J. Dong, and D. Zhang, "A supply chain network equilibrium model," Transportation Research Part E, vol. 38, no. 5, pp. 281-303, 2002.

[43] J. Dong, D. Zhang, and A. Nagurney, "A supply chain network equilibrium model with random demands," European Journal of Operational Research, vol. 156, no. 1, pp. 194-212, 2004.

[44] A. Nagurney and F. Toyasaki, "Reverse supply chain management and electronic waste recycling: a multitiered network equilibrium framework for e-cycling," Transportation Research Part E, vol. 41, no. 1, pp. 1-28, 2005.

[45] A. Nagurney, J. Cruz, J. Dong, and D. Zhang, "Supply chain networks, electronic commerce, and supply side and demand side risk," European Journal of Operational Research, vol. 164, no. 1, pp. 120$142,2005$.

[46] R. C. Savaskan, S. Bhattacharya, and L. N. Van Wassenhove, "Closed-loop supply chain models with product remanufacturing," Management Science, vol. 50, no. 2, pp. 239-252, 2004.

[47] W. E. Walsh and M. P. Wellman, "Decentralized supply chain formation: a market protocol and competitive equilibrium analysis," Journal of Artificial Intelligence Research, vol. 19, pp. 513-567, 2003.

[48] H. Wang, M. Guo, and J. Efstathiou, "A game-theoretical cooperative mechanism design for a twoechelon decentralized supply chain," European Journal of Operational Research, vol. 157, no. 2, pp. 372388, 2004.

[49] M. T. Melo, S. Nickel, and F. Saldanha-da-Gama, "Facility location and supply chain management-a review," European Journal of Operational Research, vol. 196, no. 2, pp. 401-412, 2009.

[50] E. P. Robinson and M. Swink, "Reason based solutions and the complexity of distribution network design problems," European Journal of Operational Research, vol. 76, no. 3, pp. 393-409, 1994.

[51] E. P. Robinson and M. L. Swink, "A comparative model of facility network design methodologies," Journal of Operations Management, vol. 13, no. 3, pp. 169-181, 1995.

[52] I. S. Bakal, J. Geunes, and H. E. Romeijn, “Market selection decisions for inventory models with pricesensitive demand," Journal of Global Optimization, vol. 41, no. 4, pp. 633-657, 2008.

[53] L. Schoonbeek and P. Kooreman, "The impact of advertising in a duopoly game," International Game Theory Review, vol. 9, no. 4, pp. 565-581, 2007.

[54] S. M. Gilbert and V. Cvsa, "Strategic commitment to price to stimulate downstream innovation in a supply chain," European Journal of Operational Research, vol. 150, no. 3, pp. 617-639, 2003.

[55] Z. Bar-Shira and I. Finkelshtain, "Two-moments decision models and utility-representable preferences," Journal of Economic Behavior and Organization, vol. 38, no. 2, pp. 237-244, 1999.

[56] V. Agrawal and S. Seshadri, "Risk intermediation in supply chains," IIE Transactions, vol. 32, no. 9, pp. 819-831, 2000.

[57] X. Gan, S. P. Sethi, and H. Yan, "Channel coordination with a risk-neutral supplier and a downsiderisk-averse retailer," Production and Operations Management, vol. 14, no. 11, pp. 80-89, 2005. 


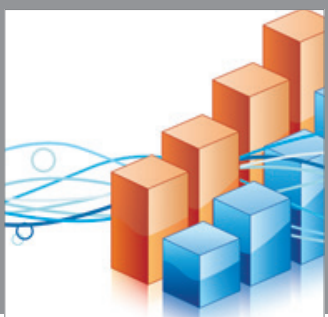

Advances in

Operations Research

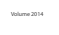

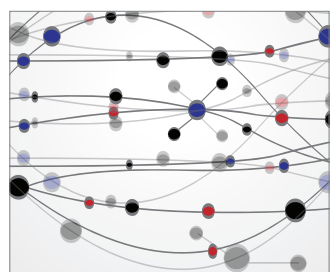

\section{The Scientific} World Journal
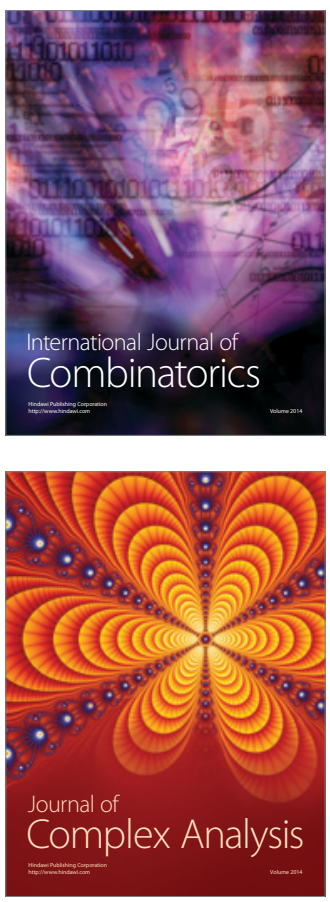

International Journal of

Mathematics and

Mathematical

Sciences
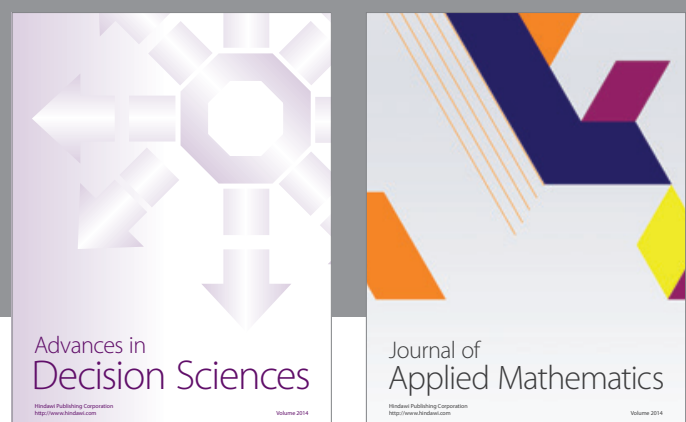

Journal of

Applied Mathematics
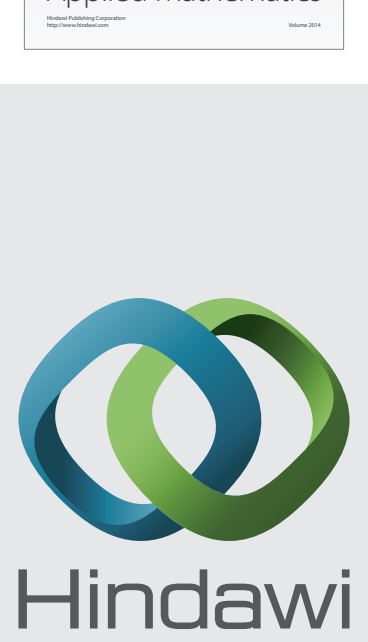

Submit your manuscripts at http://www.hindawi.com
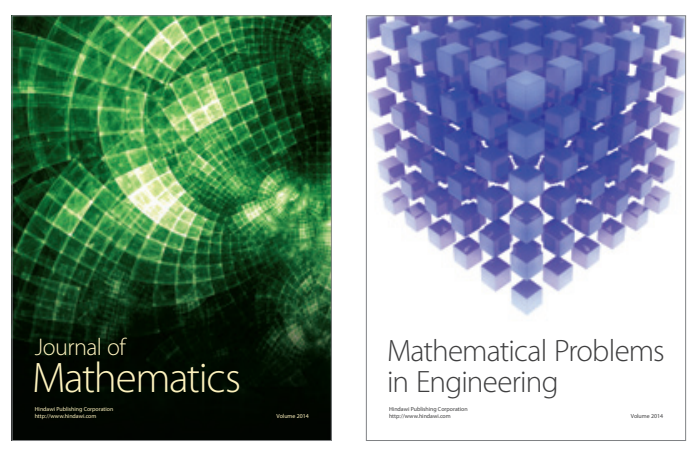

Mathematical Problems in Engineering
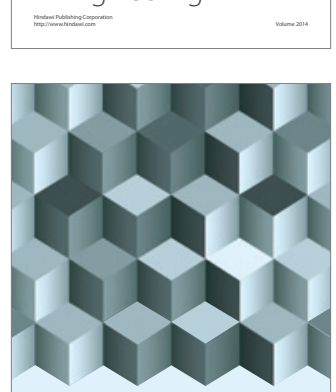

Journal of

Function Spaces
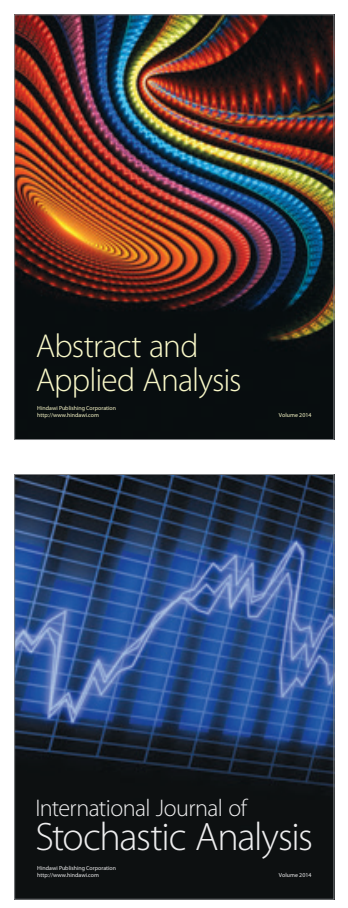

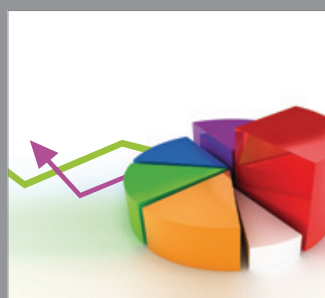

ournal of

Probability and Statistics

Promensencen
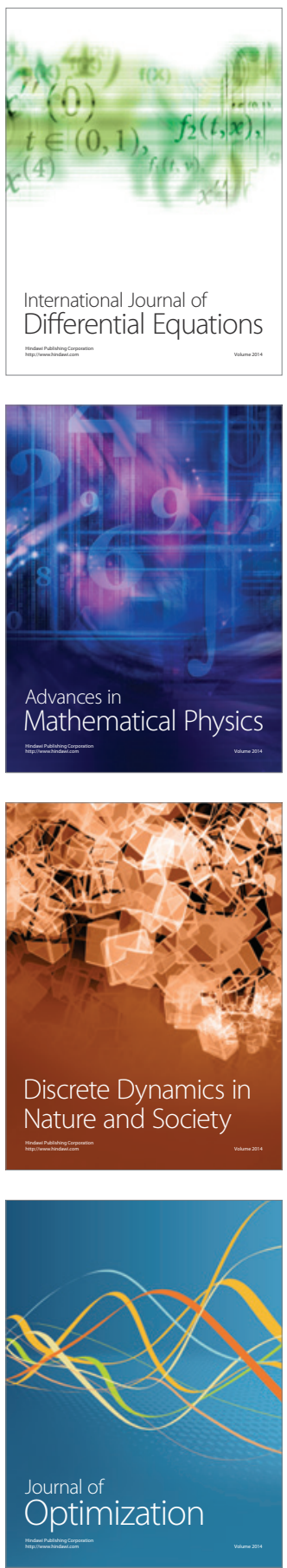